\title{
A Review of Host Plants of Cerambycidae (Coleoptera: Chrysomeloidea) with new Host Records for Fourteen Cerambycids, Including the Asian Longhorn Beetle (Anoplophora glabripennis Motschulsky), in Korea
}

\author{
Jongok Lim, Su-Young Jung ${ }^{1}$, Jong-Su Lim ${ }^{2}$, Jin Jang ${ }^{3}$, Kyung-Mi Kim ${ }^{4}$, You-Mi Lee ${ }^{1}$ and Bong-Woo Lee ${ }^{1}{ }^{*}$ \\ Departmento de Biologia, Universidade Federal do Espirito Santo, Vitoria, Espirito Santo 29040-090, Brazil \\ ${ }^{1}$ Division of Forest Biodiversity, Korea National Arboretum, Soheul-eup, Pocheon-si, Gyeonggi-do 487-821, Republic of Korea \\ ${ }^{2}$ Yeongwol Donggang Ecological Park, Samok-ri, Yeongwol-eub, Yeongwol-gun, Gangwon-do 230-888, Republic of Korea \\ ${ }^{3}$ Division of Experiment and Analysis, Incheon International Airport, Regional Office Animal and Plant Quarantine Agency, Woonseo-dong, Jung-gu, \\ Incheon 400-718, Republic of Korea \\ ${ }^{4}$ Usan-Sangwon Technical Development Co., Ltd., Usan-dong, Gwangsan-gu, Gwangju 506-814, Republic of Korea
}

\section{유리알락하늘소를 포함한 14종 하늘소의 새로운 기주식물 보고 및 한국산 하늘소과 딱정벌리목: 잎벌리상과의 기주식물 재검토}

\author{
임종옥 · 정수영 $\cdot$ 임종수 ${ }^{2} \cdot$ 장 진 $^{3} \cdot$ 김경미 $^{4} \cdot$ 이유미 ${ }^{1} \cdot$ 이봉우 ${ }^{*}$ \\ 브라질 에스피리토 산토 연방대학교 생물학과, ${ }^{17}$ 굽립수목원 산림생물조사과, ${ }^{2}$ 영월동강생태공원, ${ }^{3}$ 농림축산검역본부 인천국제공항 시험분석과, ${ }^{4}$ 상원기술개발
}

\begin{abstract}
A revised checklist of host plants for 181 species belonging to 103 genera in six subfamilies of Cerambycidae (Coleoptera: Chrysomeloidea) in Korea is provided on the basis of the results of field surveys and literature review. A total of 14 new cerambycid-host associations are confirmed and the Manchurian striped maple, Acer tegmentosum Maxim. (Aceraceae), is listed as a new host of the Asian longhorn beetle, Anoplophora glabripennis (Motschulsky). The names of more than 170 host plants species belonging to 107 genera in 44 families are compiled. Among them, four families (Ulmaceae, Pinaceae, Fagaceae and Betulaceae) are confirmed as the main host families (more than 23\%) of most of the cerambycid species. All invalid scientific names and Korean names of plants and cerambycids in the previous literature are corrected in the present paper.
\end{abstract}

Key words: Long-horned beetle, Wood-boring insect, Larvae, Host plant, Korea

초 록: 직접적인 기주식물 조사와 기존 문헌자료의 기록을 재검토하여, 한국산 하늘소과(딱정벌레목: 잎벌레상과) 6 아과 103 속 181 종의 기주식물 목록을 작성하였다. 유리알락하늘소의 새로운 기주식물로 산겨릅나무가 확인된 것을 포함하여 총 14 종의 하늘소와 기주식물 관계를 구명하였다. 기주식물로 44 과 107속 170 종 이상이 정리되었다. 이 중, 네 과(느릅나무과, 소나무과, 참나무과, 자작나무과)가 주요 기주식물 과(하늘소 기록종 수의 $23 \%$ 이상 차지)인 것으로 확인되었다. 기존 문헌들에서 기주식물과 하늘소류의 무효한 학명과 국명들은 현재 통용하고 있는 유효한 학명과 국명으로 수정하였다.

검색어: 하늘소, 천공성 곤충, 유충, 기주식물, 한국

The Cerambycidae are one of species rich family of Chrysomeloidea (Insecta: Coleoptera), and all members are

*Comesponding author: eucosma@korea.kr

Received September 13 2013; Revised November 282013 Accepted February 52014 commonly called as longhorn beetles, long-horned beetles or longicorn beetles.

The family are comprised of approximately 25,000 described species in nine subfamilies worldwide (Sama et al., 2010; Bouchard et al., 2011) and 318 species are known from 
the Korean fauna (Lee, 1987; Danilevsky, 1992; Paek et al., 2010; Danilevsky, 2013; Lim et al., 2012, 2013a, b; Oh, 2013; Oh and Lee, 2013) since Kolbe (1886) recorded first Korean cerambycids.

Cerambycids inhabit deciduous and coniferous forests, large open meadows, steppes and semi-deserts. Most species are associated with woods and shrubs, live on herbaceous vegetation in open areas (Cherepanov, 1988). The larvae cause damages of host plants by boring into heart wood and making galleries. In many cases, it is not easy to recognize damage on plants when larvae are at early stages of development.

Adults of many species of the subfamily Lepturinae are well known pollinators (Fig. 1A). On the other hand, several cerambycids have been categorized as economic pests because they can seriously debilitate or kill commercial and ornamental plants as well as cause severe damage to timber already in service (Webb, 1987).

For instance, Monochamus species (Fig. 1B) are known as vectors of the pine wood nematode (Bursaphelenchus xylophilus (Steiner \& Buhrer)) which causes devastating damage on pine forests in North America, East Asia and Europe. Another example is the Asian longhorned beetle, Anoplophora grabripennis (Motschulsky) (Fig. 3), that is considered to be one of the most damaging exotic forest insects that have established in the United States during recent years (the established populations of the beetle were first reported in 1996) (Haack et al., 1997; 2006) and it has been causing serious economic damage on a wide range of hardwood trees, including maple (Fig. 1C).

In Korea, more than 130 cerambycids were listed as insect pests of woody plants and shrubs, and 11 species of them, such as Batocera lineolata Chevrolat, are regarded as major wood-boring insect pests in the forest (Ko, 1969; Chung et al., 1995).

Up to now, many studies on host plants of cerambycid beetles have been carried out at national or biogeographic level (Halperin and Holzschuh, 1993; Di lorio, 1997; Linsley and Chemsak, 1997; Hua, 2002; Sama, 2002; Kojima and Nakamura, 2011; MacRae et al., 2012).

In Korea, the first extensive study on host plants of cerambycids (125 species) was made by Cho (1959) and a summarized list of cerambycid pests and their hosts were provided by Ko (1969) and Chung et al. (1995). Later, Kang et al. (2002) also listed up the host plants of 85 cerambycid species. However, scientific names and Korean names in those works were mostly outdated so that they need to be updated with names currently in use.

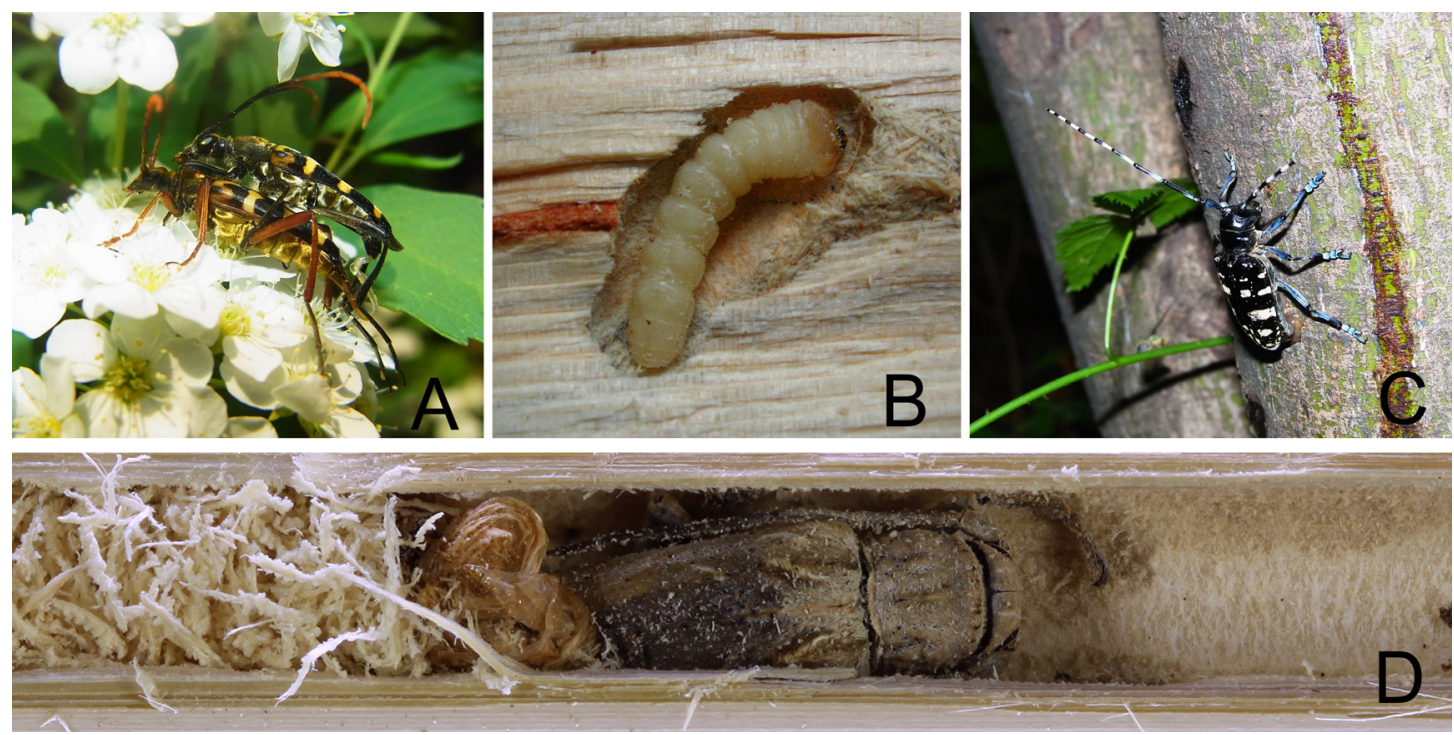

Fig. 1. Two ecological aspects of Cerambycidae. A, Leptura arcuata as pollinator on a plant, Viburnum opulusf. hydrangeoides (Nakai) Hara (Caprifoliaceae); B, insect pest, a larva of Monochamus salturius as a vector of the pine wood nematode within a host, Pinus koraiensis Siebold \& Zucc. (Pinaceae); C, a female of Anoplophora grabripennis (Mot.), ovipositing eggs into a host, Acer tegmentosum Maxim. (Aceraceae); D, an adult of Niphona furcata within a host, Pseudosasa japonica (Siebold \& Zucc. ex Steud.) Makino (Gramineae). 
The aims of the present paper are 1) to provide the valid scientific names and Korea names of previously recorded species of cerambycids and hosts, 2) to clarify a checklist of the Korean cerambycids-host associations by review the previous literatures and direct investigations.

\section{Materials and Methods}

We selectively collected immature stages of Cerambycidae in determined host plants or gathered all of stems and twigs which were infested and damaged by cerambycid larvae from 2010 to 2013 . We brought the collected samples of immature stages of cerambycids and host plants to laboratory.

We stored the gathered host plants in plastic cages. Some of collected larvae were reared within their host plants in plastic cages $(56 \mathrm{~cm} \times 39 \mathrm{~cm} \times 30 \mathrm{~cm})$ or in a small petri dish $(5.3 \mathrm{~cm}$ $\times 1.9 \mathrm{~cm}$ ) in laboratory condition. Also, we labeled the information on host plant, collection date, collection locality and GPS (longitude, latitude, altitude) data on the outside of the plastic cages.

We checked the emergence of adults from each host plant every day. The specimens were determined to species level by the first author and deposited in the Insect Collection of Korea National Arboretum (Pocheon, Korea), Korea Forest Service.
For the literature review, we selected nine representative papers and books (Cho, 1959; Ko, 1969; Lee, 1987; Chung et al., 1995; Kang et al., 2002; Williams et al., 2004; Shin et al., 2007; Lim et al., 2013a, b), which considered the relationships between host plants and the Korean cerambycid species. The scientific name of host plants followed the "Korean Plant Names Index (http://www.nature.go.kr/kpni)" by Korea Forest Service and the Korean names of foreign plant species whose distribution in the Korean peninsula are suspicious in original literatures were cited.

The abbreviations of subfamilies in figures and appendix 1 as follow: CE, Cerambycinae; DI, Disteniinae; LA, Lamiinae; LE, Lepturinae; PR, Prioninae; SP, Spondylidinae.

All previous scientific and Korean names of cerambycids and host plants are replaced with the current name.

\section{Results and Discussion}

\section{New Host Plants of Korean Cerambycidae with a literature review of known hosts for all Korean Cerambycidae}

As a result of our direct investigation of host plants and cerambycids in Korea, we found fourteen new host-cerambycid

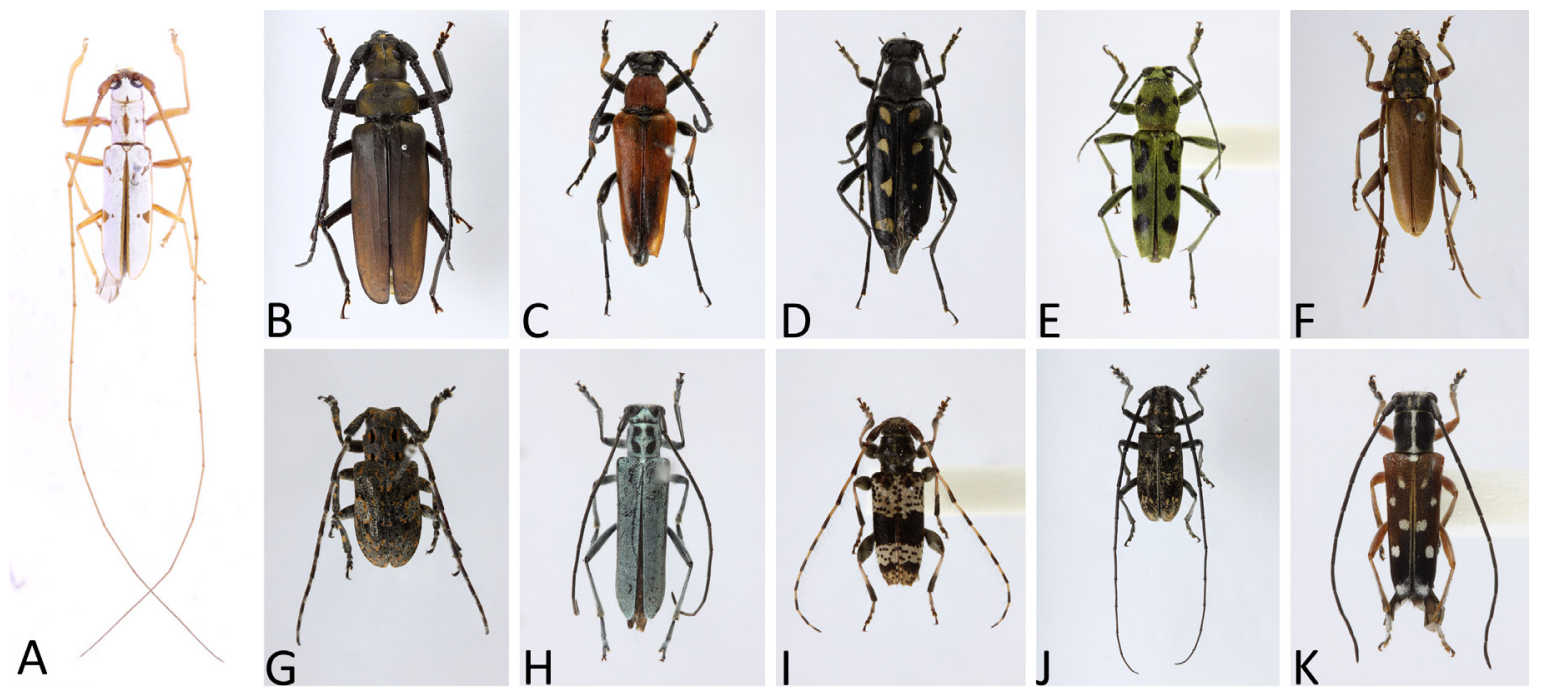

Fig. 2. Cerambycids for which the new host plants have been confirmed in this study (A, Olenecamptus formosanus Pic; B, Megopis sinica (White); C, Corymbia rubra (Linnaeus); D, Leptura duodecimguttata Fabricius; E, Chlorophorus simillimus (Kraatz); F, Margites fulvidus (Pascoe); G, Mesosa myops (Dalman); H, Eumecocera impustulata (Motschulsky); I, Rhopaloscelis unifasciatus Blessig; I, Monochamus saltuarius (Gebler); K, Glenea relicta (Pascoe). 
associations as follows:

Subfamily Prioninae Latreille (Korean Name: Top-ha-neulso-a-gwa)

1) Eight adults of Megopis sinica (White, 1853) (K.N.: Beo-deul-ha-neul-so) (Fig. 2B)

- Carpinus laxiflora (Siebold \& Zucc.) Blume (Betulaceae).

Subfamily Lepturinae Latreille (K.N.: Ggot-ha-neul-so-a-gwa)

2) One adult of Corymbia rubra (Linnaeus, 1758) (K.N.: Bul-geun-san-ggot-ha-neul-so) (Fig. 2C)

- Pinus japonica (Thunb.) Steud. (Pinaceae).

3) Three adults of Leptura duodecimguttata Fabricius, 1801 (K.N.: Yeol-du-jeom-bak-i-ggot-ha-neul-so) (Fig. 2D)

- Malus pumila Mill. (Rosaceae).

Subfamily Cerambycinae Latreille (K.N.: Ha-neul-so-a-gwa)

4) One adult of Ceresium longicorne Pic, 1926 (K.N.: Seom-ha-neul-so) - Quercus acuta Thunb. (Fagaceae).

5) Two adults of Chlorophorus simillimus (Kraatz, 1879) (K.N.: Yeuk-jeom-bak-i-ha-neul-so) (Fig. 2E) - Juglans regia L. (Juglandaceae).

6) One adult of Margites fulvidus (Pascoe, 1858) (K.N.: Jak-eun-ha-neul-so) (Fig. 2F) - Quercus acuta Thunb. (Fagaceae).

\section{Subfamily Lamiinae Latreille (K.N.: Mok-ha-neul-so-a-gwa)}

7) Two adults of Olenecamptus formosanus Pic, 1914 (K.N.: Gul-pi-yeom-so-ha-neul-so) (Fig. 2A) - Morus alba L. (Moraceae).

8) Four adults of Mesosa myops (Dalman, 1817) (Fig. 2G) (K.N.: Ggae-da-si-ha-neul-so) - Juglans mandshurica Maxim. (Juglandaceae).

9) One adult of Eumecocera impustulata (Motschulsky, 1943) (K.N.: Dang-na-gui-ha-neul-so) (Fig. 2H) - Carpinus laxifolora (Siebold \& Zucc.) Blume.

10) Seven adults of Rhopaloscelis unifasciatus Blessig, 1873 (K.N.: Mu-nui-gon-bong-ha-neul-so) (Fig. 2I) - Juglans regia L. (Juglandaceae).

11) Fourteen adults of Monochamus saltuarius (Gebler, 1830) (K.N.: Buk-bang-su-yeom-ha-neul-so) (Fig. 2J) - Picea abies (L.) H.Karst. (Pinaceae).
12) Twenty-eight adults of Moechotypa diphysis (Pascoe, 1871) (K.N.: Teol-du-ggeo-bi-ha-neul-so) - Juglans mandshurica Maxim. (Juglandaceae), Quercus acuta Thunb. (Fagaceae).

13) Eight adults of Glenea relicta Pascoe, 1858 (K.N.: Huin-jeom-ha-neul-so) (Fig. 2K) - Quercus acuta Thunb. (Fagaceae).

14) More than twenty adults of Anoplophora glabripennis (Motschulsky, 1853) (K.N.: Yu-ri-al-rak-ha-neul-so) (Fig. 3) - Acer tegmentosum Maxim. (Aceraceae).

There are some advantages of rearing of immature stages of Cerambycidae in laboratory conditions. For example, many new species and new records have been found by rearing the immature samples from their hosts (Georgiev et al., 2005; Friedman et al., 2008; Lim et al., 2006, 2013a, b; Berkov and Monné, 2010), as well as useful natural enemies of cerambycids can be found by rearing (Tozlu and Kara,
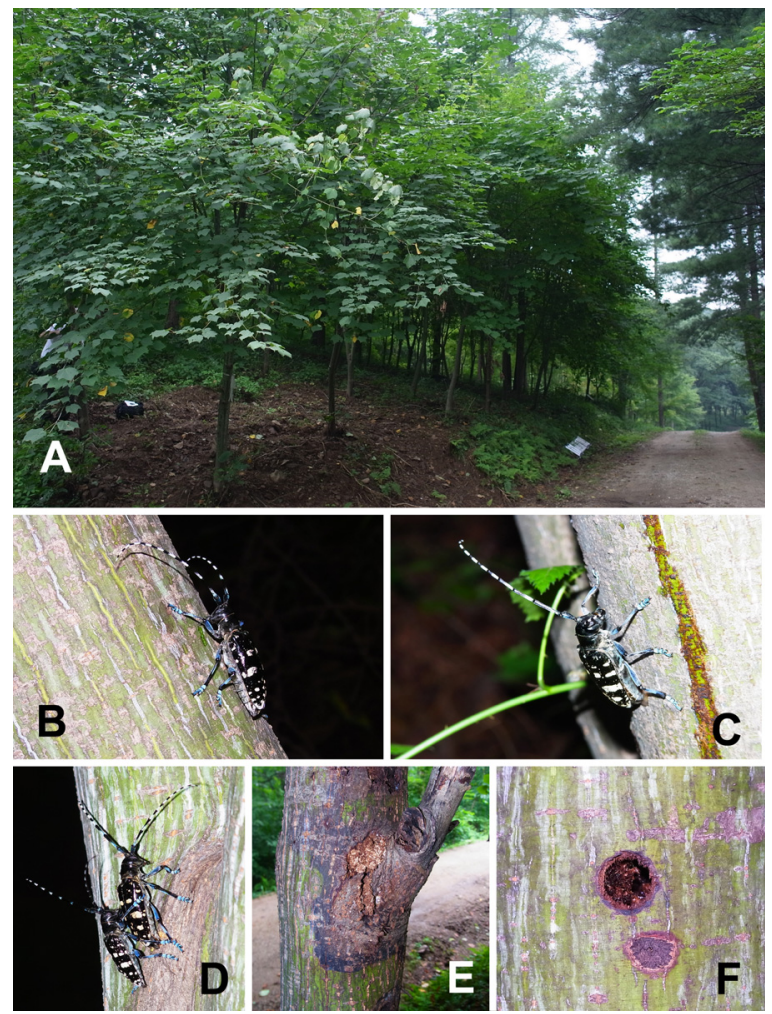

Fig. 3. Habitats (A) and ecological pictures $(\mathrm{B}-\mathrm{F})$ of Anoplophora glabripennis (Motschulsky) (A, habitats, a plantation of the host plant, Acer tegmentosum Maxim. in Gwangneung forest, Pocheon, Korea; B, chewing barks for oviposition; C, oviposition; $D$, oviposition after copulation; $E$, exposed frasses from the galleries by larvae; $F$, emergence hole). 
Table 1. The number of subfamilies, genera and species of cerambycids for each host plant (family level) (The names of the hosts are arranged in descending order of the number of species of Cerambycidae)

\begin{tabular}{|c|c|c|c|c|c|}
\hline \multirow{2}{*}{ No. } & \multicolumn{2}{|c|}{ HOST PLANT (family) } & \multicolumn{3}{|c|}{ CERAMBYCIDAE } \\
\hline & Scientific name & Korean name & No. subfamily & No. genus & No. species (\%) \\
\hline 1 & Ulmaceae & 느릅나무과 & 4 & 33 & $48(26.5)$ \\
\hline 2 & Pinaceae & 소나무과 & 6 & 32 & $46(25.4)$ \\
\hline 3 & Fagaceae & 참나무과 & 4 & 38 & $45(24.9)$ \\
\hline 4 & Betulaceae & 자작나무과 & 6 & 28 & $42(23.2)$ \\
\hline 5 & Rosaceae & 장미과 & 4 & 28 & $35(19.3)$ \\
\hline 6 & Salicaceae & 버드나무과 & 5 & 29 & $34(18.8)$ \\
\hline 7 & Juglandaceae & 가래나무과 & 2 & 20 & $26(14.4)$ \\
\hline 8 & Moraceae & 뽕나무과 & 4 & 17 & $24(12.7)$ \\
\hline 9 & Leguminosae & 콩과 & 3 & 16 & $21(11.6)$ \\
\hline 10 & Vitaceae & 포도과 & 2 & 8 & $14(7.7)$ \\
\hline 11 & Rutaceae & 운향과 & 2 & 7 & $13(7.2)$ \\
\hline 12 & Aceraceae & 단풍나무과 & 4 & 9 & $11(6.1)$ \\
\hline 13 & Euphorbiaceae & 대극과 & 3 & 7 & $9(5.0)$ \\
\hline 14 & Taxodiaceae & 낙우송과 & 4 & 8 & $8(4.4)$ \\
\hline 15 & Oleaceae & 물푸레나무과 & 3 & 7 & $7(3.9)$ \\
\hline 16 & Cornaceae & 층층나무과 & 3 & 6 & $7(3.9)$ \\
\hline 17 & Ebenaceae & 감나무과 & 2 & 6 & $7(3.9)$ \\
\hline 18 & Tiliaceae & 피나무과 & 2 & 6 & $7(3.9)$ \\
\hline 19 & Cupressaceae & 측백나무과 & 3 & 6 & $6(3.3)$ \\
\hline 20 & Lauraceae & 녹나무과 & 2 & 6 & $6(3.3)$ \\
\hline 21 & Araliaceae & 두릅나무과 & 2 & 4 & $6(3.3)$ \\
\hline 22 & Scrophulariaceae & 현삼과 & 3 & 5 & $5(2.8)$ \\
\hline 23 & Gramineae & 벼과 & 2 & 3 & $3(1.7)$ \\
\hline 24 & Compositae & 국화과 & 1 & 3 & $3(1.7)$ \\
\hline 25 & Actinidiaceae & 다래나무과 & 2 & 2 & $2(1.1)$ \\
\hline 26 & Anacardiaceae & 옻나무과 & 2 & 2 & $2(1.1)$ \\
\hline 27 & Caprifoliaceae & 인동과 & 2 & 2 & $2(1.1)$ \\
\hline 28 & Elaeagnaceae & 보리수나무과 & 1 & 2 & $2(1.1)$ \\
\hline 29 & Lythraceae & 부처꽃과 & 1 & 2 & $2(1.1)$ \\
\hline 30 & Punicaceae & 석류나무과 & 1 & 2 & $2(1.1)$ \\
\hline 31 & Rhamnaceae & 갈매나무과 & 1 & 2 & $2(1.1)$ \\
\hline 32 & Styracaceae & 때죽나무과 & 1 & 2 & $2(1.1)$ \\
\hline 33 & Meliaceae & 멀구슬나무과 & 1 & 1 & $2(1.1)$ \\
\hline 34 & Platanaceae & 버즘나무과 & 1 & 1 & $2(1.1)$ \\
\hline 35 & Cannabaceae & 삼과 & 1 & 1 & $1(0.6)$ \\
\hline 36 & Casuarinaceae & 목마황과 & 1 & 1 & $1(0.6)$ \\
\hline 37 & Cucurbitaceae & 박과 & 1 & 1 & $1(0.6)$ \\
\hline 38 & Daphniphyllaceae & 굴거리나무과 & 1 & 1 & $1(0.6)$ \\
\hline 39 & Ginkgoaceae & 은행나무과 & 1 & 1 & $1(0.6)$ \\
\hline 40 & Malvaceae & 아욱과 & 1 & 1 & $1(0.6)$ \\
\hline 41 & Myrtaceae & 도금양과 & 1 & 1 & $1(0.6)$ \\
\hline 42 & Simaroubaceae & 소태나무과 & 1 & 1 & $1(0.6)$ \\
\hline 43 & Sterculiaceae & 벽오동과 & 1 & 1 & $1(0.6)$ \\
\hline 44 & Urticaceae & 쐐기풀과 & 1 & 1 & $1(0.6)$ \\
\hline \multicolumn{3}{|c|}{ Total } & 6 & 103 & $181(100.0)$ \\
\hline
\end{tabular}




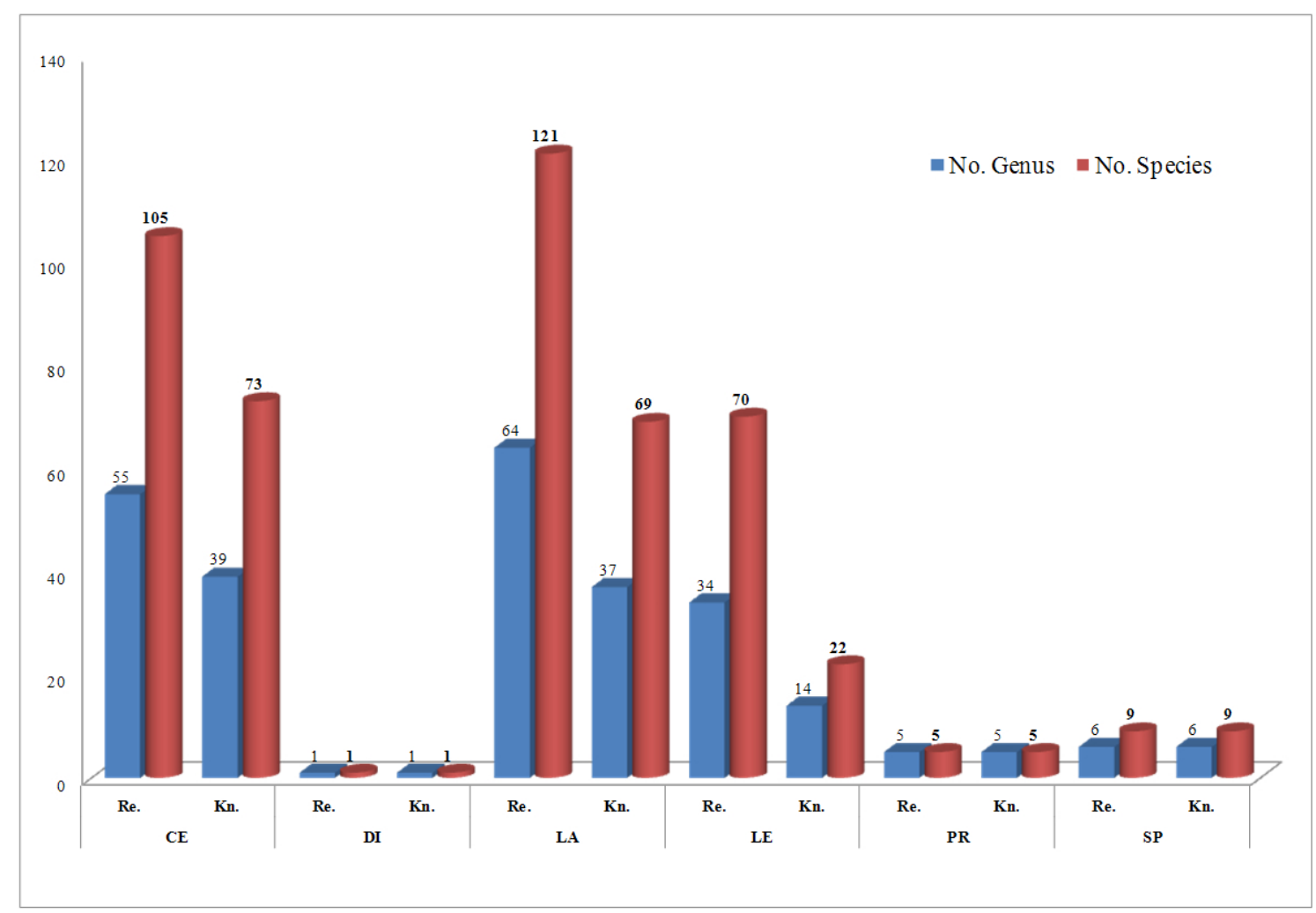

Fig. 4. Comparison of the number of recorded cerambycid genera/species from the Korean peninsula and the number of genera/species that their host have been recorded (Re., recorded number of genera and species of cerambycids; Kn., number of genera and species that their host have been recorded) (CE, Cerambycinae; DI, Disteniinae; LA, Lamiinae; LE, Lepturinae; PR, Prioninae; SP; Spondylinae).

2007; Sheng et al., 2012; Tindall and Fothergill, 2012).

To understand and update a checklist of the host plants of phytophagous insects are essential, fundamental and very important process. We can know the host diversity itself in nature and relationships among human, insects and hosts. Furthermore, we can apply our knowledements on host plants to applied areas such as plant quarantine services, making policies, conservation of biodiversity and ecological researches on the phytophagous insects.

Up to now, although around 318 species of cerambycids have been recorded from Korea, most studies on host plants of them have focused on the pests of agricultural or forestry products, and there are not enough fundamental data of Korean Cerambycidae, due to the insufficiency of specialists of taxonomy and ecology on cerambycids.

In China, A. glabripennis (Mot.) is a pest of man-made landscapes, including windbreaks, greenbelts, ornamental plantings in urban areas, and plantations or shelter-forests, where they undergo cyclical outbreaks (Hsiao, 1982). These landscapes are typically mono-cultures or of very limited species diversity, often composed of fast growing non-native tree species introduced from Europe and other countries (Smith et al., 2009). In the present study, the Manchurian striped maple, Acer tegmentosum Maxim., is newly confirmed as a host plant in South Korea. The habitat consists of more than fifty $A$. tegmentosum trees (Fig. 3A) and we could find copulation of many adults, oviposition of females (Fig. 3C), frasses (Fig. 3E) and emergence holes (Fig. 3F).

In the present paper, 44 families of host plants for Korean Cerambycidae are summarized. And among them, four families (Ulmaceae, Pinaeceae, Fagaceae and Betulaceae) are confirmed as main host families of known cerambycids by about $30 \%$ and more than $23 \%$ of species, respectively (Table 1). It is also confirmed that two families, Pinaceae and Betulaceae are attacked by all known subfamilies of Cerambycidae while most families except for nine families of host plants are attacked by only a few species of Cerambycidae (< 10 spp.). These data can be used to 
construct a forest or a garden for attracting various species of Cerambycidae in the area.

In Korea, the host plants of three small subfamilies, Disteniinae, Prioninae and Spondylidinae, are mostly known $(100 \%)$ (Fig. 4). On the other hands, we made effort to discover more hosts of genera and species of remained subfamilies, Cerambycinae, Lamiinae and Lepturinae, which most beneficial species or pests are belonging in. As a result, the host plants of $70 \%$ of recorded genera and species in Cerambycinae were known (Fig. 4) and less than $60 \%$ and less than $50 \%$ compare to the number of recorded genera and species were are known in Lamiinae and Lepturinae, respectively (Fig. 4).

Additionally, in the present paper, we summarized all recorded host plants of Korean cerambycids based on the direct investigations and previously published data.

A revised and updated checklist of host plants of Korean Cerambycidae is presented (Appendix 1).

\section{Acknowledgements}

We thank to Dr. S. W. Lingafelter (USDA, Smithsonian Institution, National Museum of Natural History, Washington D.C., USA) and Dr. I. K. Kim (Korea National Arboretum, Pocheon, South Korea) for reviewing the present manuscript; Ms. S.Y. Park (KNA) for her help on collection immature stages of cerambycids and Ms. H.J. Lee (KNA) in her effort to find correct scientific and Korean names of host plants; Dr. F. Herard (USDA, Agricultural Research Service, European Biological Control Laboratory, Montferrier-sur-Lez, France) and Mr. H.S. Song (Seoul National University, Seoul, South Korea) for their kind cooperation. This study was supported by Forest Science \& Technology Project (Project No. S121212L110140) provided by the Korea Forest Service.

\section{Literature Cited}

Bense, U., 1995. Longhorn beetles. Illustrated key to the Cerambycidae and Vesperidae of Europe. Druckerei Steinmeier, Nördlingen, Germany.

Berkov, A., Monné, M.A., 2010. A new species Neobaryssinus
Monné \& Martins, and two new species of Baryssiniella new genus (Coleoptera: Cerambycidae), reared from trees in the Brazil nut family (Lecythidaceae). Zootaxa, 2538, 47-59.

Bouchard, P., Bousquet, Y., Davies, A.E., Alonso-Zarazaga, M.A., Lawrence, J.F., Lyal, C.H.C., Newton, A.F., Reid C.A.M., Schmitt, M., Ślipiński, S.A., Smith, A.B.T., 2011. Family-group names in Coleoptera (Insecta). Zookeys 88, 1-972.

Cherepanov, A.I., 1988. Cerambycidae of Northern Asia. Vol. I. Prioninae, Disteniinae, Lepturinae, Aseminae. Amerind Publishing Co. Pvt. Ltd., New Delhi.

Cho P.S., 1959. A study on the damaged plants of longicorn beetles in Korea (Cerambycidae). Collected papers of Shinheung College 2, 355-386.

Chung, Y.J., Lee, B.Y., Byun, B.H., 1995. A List of Insect Pests of Trees and Shrubs in Korea. Forestry Research Institute, Seoul, Korea.

Danilevsky, M.L., 1992. New species of Cerambycidae (Coleoptera) from East Asia with some new records. Annls. Hist. Nat. Mus. Nat. Hung., 84, 111-116.

Danilevsky, M.L., 2013. Six new Longicorn (Coleoptera, Cerambycidae) taxa from Russia and adjacent countries. Humanity space. International almanac, 2(2), 28-41.

Di lorio, O.R., 1997. Host plants of Cerambycidae (Coleoptera) from northwest and central Argentina. Rev. Biol. Trop., 44-45, 149-158.

Friedman, A.L.L., Rittner, O., Chikatunov, V.I., 2008. Five new species of longhorn beetles (Coleoptera: Cerambycidae) in Israel. Phytoparasitica, 36 (3), 242-246.

Goergiev, G., Simov, N., Stojanova, A., Doychev, D., 2005. New and interesting records of longhorn beetles (Coleoptera: Cerambycidae) in some Bulgarian mountains. Acta Zool. Bulgar., 57 (2), 131-138.

Haack, R.A., Law, K.R., Mastro, V.C., Ossenbruggen, H.S., Raimo, B.J., 1997. New York's battle with the Asian long-horned beetle. Journal of Forestry, 95 (12), 11-15.

Haack, R.A., Bauer, L.S., Gao, R.T., McCarthy, J.J., Miller D.L., Petrice, T.R., Poland, T.M., 2006. Anoplophora glabripennis within-tree distribution, seasonal development, and host suitability in China and Chicago. Gt. Lakes Entomol., 39 (3, 4), 169-183.

Halperin J., Holzschuh, C., 1993. Host-Plants of Israeli Cerambycidae (Coleoptera), with New Records. Phytoparasitica, 21 (1), 23-37.

Hsiao, K.J., 1982. Forest entomology in China: A general review. Crop Prot., 1: 359-367.

Hua, L.Z., 2002. List of Chinese Insects. Vol. II. Zhong-shan University, Guangzhou.

Kang E.Y, Oh, H.Y, Oh, H.Y., 2002. A larval hostplant list of the Cerambycidae (Coleoptera) in South Korea. Lucanus, 3, 1-5.

Ko, J.H., 1969. A List of Insect Pests of Trees and Shrubs in Korea. Forestry Research Institute, Seoul, Korea. 
Kojima, K., Nakamura, S., 2011. Food plants of cerambycid beetles (Cerambycidae, Coleoptera) in Japan (revised and enlarged edition). Hiba Society of Natural History. Hiroshima, Japan.

Kolbe, H.J., 1886. Beiträge zur Kenntniss der Coleopteren-Fauna Koreas, bearbeitet auf Grund der von Herrn Dr. C. Gottsche während der Jahre 1883 und 1884 in Korea veranstalteten Sammlung; nebst Bemerküngen über die zoogeographischen Verhältnisse dieses Faunengebietes und Untersuchungen uber einen Sinnesapparat in Gaumen von Misolampidius morio. Archiv fur Naturgeschichte, 52 (1): 139-240.

Lee, S.M., 1987. The Longicorn Beetles of Korean Peninsula. National Science Museum, Seoul.

Lim, J., Lyu, D., Choi, G.S., Jeong, Y.J., Shin, S.C., Lee, S., 2006. A taxonomic note on Sclerodermus harmandi, ectoparasite of stem and wood boring insect larvae (Hymenoptera: Chrysidoidea: Bethylidae) in South Korea. J. Asia-Pacific Entomol., 9 (2), 115119.

Lim, J., Han, Y., Lee, B., Oh, H., Lyu, D., 2012. A new species of Clytus Laicharting (Coleoptera: Cerambycidae) from Korea with a key to Korean species. Entomol. Res., 42, 192-195.

Lim, J., Kim, I.K., Lee, Y.S., Kim, K.M., Kim, C.H., Lim, J.S., Park, S.Y., Lee, B.W., 2013a. Three species of Phymatodes Mulsant (Coleoptera: Cerambycidae) new to South Korea that hosted on Vitis vinifera Linnaeus (Vitaceae). Entomol. Res., 43, 34 -39 .

Lim, J., Lim, J.S., Lee, B.W., 2013b. A new species of Eupogoniopsis and new record of Eupromus ruber (Dalman) (Coleoptera: Cerambycidae) from South Korea. Entomol. Res., 43, 358-364.

Linsley, E.G., Chemsak, J.A., 1997. The Cerambycidae of North America, Part VIII: Bibliography, Index, and Host Plant Index. University of California Press. London, England.

MacRae, T.C., Bezark, L.G, Swift, I., 2012. Notes on distribution and host plants of Cerambycidae (Coleoptera) from southern Mexico. Pan-Pac. Entomol., 88 (2), 173-187.

Oh, S.H., 2013. Two additional species of the subfamily Cerambycinae (Coleoptera, Cerambycidae) from the Korean Peninsula. Elytra, Tokyo, New Series, 3(1), 161-163.

Oh, S.H., Lee, S.H., 2013. Four species of the subfamily Lamiinae (Coleoptera, Cerambycidae) newly recorded from Korea. Elytra,
Tokyo, New Series, 3(2): 301-304.

Paek, M.K., Hwang, J.M., Jung, K.S., Kim, T.W., Kim, M.C., Lee, Y.J., Cho, Y.B., Park, S.W., Lee, H.S., Ku, D.S., Jeong, J.C., Kim, K.G., Choi, D.S., Shin, E.H., Hwang, J.H., Lee, J.S., Kim, S.S., Bae, Y.S., 2010. Checklist of Korean insects. <Nature \& Ecology> Academic Series 2, Seoul, Korea.

Sama, G., 2002. Atlas of the Cerambycidae of Europe and the Mediterranean Area. Vol. I. Northern, Western, Central and Eastern Europe British Isles and Continental Europe from France (excl. Corsica) to Scandinavia and Urals. Nakladatelství Kabourek, Zlín, Russia.

Sama, G., Buse, J., Orbach, E., Friedman, A.L.L., Rittner, O., Chikatunov, V., 2010. A new catalogue of the Cerambycidae (Coleoptera) of Israel with notes on their distribution and host plants. Munis Ent. Zool., 5 (1), 1-51.

Sheng, M.L., Zhao, R.X., Sun, S.P., 2012. A new species of Xorides Latreille (Hymenoptera, Ichneumonidae, Xoridinae) parasitizing Pterolophia alternata (Coleoptera, Cerambycidae) in Robinia pseudoacacia. Zookeys, 246, 39-49.

Shin, S.C., Choi, G.S., Chung, Y.J., Lee, S.G., Kim, C.S., 2007. A new illustrated guide to Korean Insect Pests of Trees and Shrubs. Forestry Research Institute, Seoul, Korea.

Smith, M.T., Turgeon, J.J., Groot, P.D., Gasman, B., 2009. Asian longhorned beetle, Anoplophora glabripennis (Motschulsky): Lessons learned and opportunities to improve the process of eradication and management. Am. Entomol., 55 (1): 21-25.

Tindall, K.V., Fothergill, K., 2012. Dolichomitus irritator (Hymenoptera: Ichneumonidae):a new parasite of Dectes texanus (Coleoptera: Cerambycidae) in soybeans. Fla. Entomol., 95 (1), 238-240.

Tozlu, G., Kara, K., 2007. The first host record for Zeuxia zejana Kolomiets, 1971 (Diptera: Tachinidae) from Turkey. Turk. J. Zool., 31, 357-358.

Webb, G.A., 1987. Laval host plants of Cerambycidae (Coleoptera) held in some Australian insect collections. Forestry Commission of New South Wales. 1-19.

Williams, D.W., Lee, H.P, Kim, I.K., 2004. Distribution and abundance of Anoplophora glabripennis (Coleoptera: Cerambycidae) in natural Acer stands in South Korea. Environ. Entomol., 33 (3), 540-545. 
Appendix 1. A checklist of host plants of Korean Cerambycidae

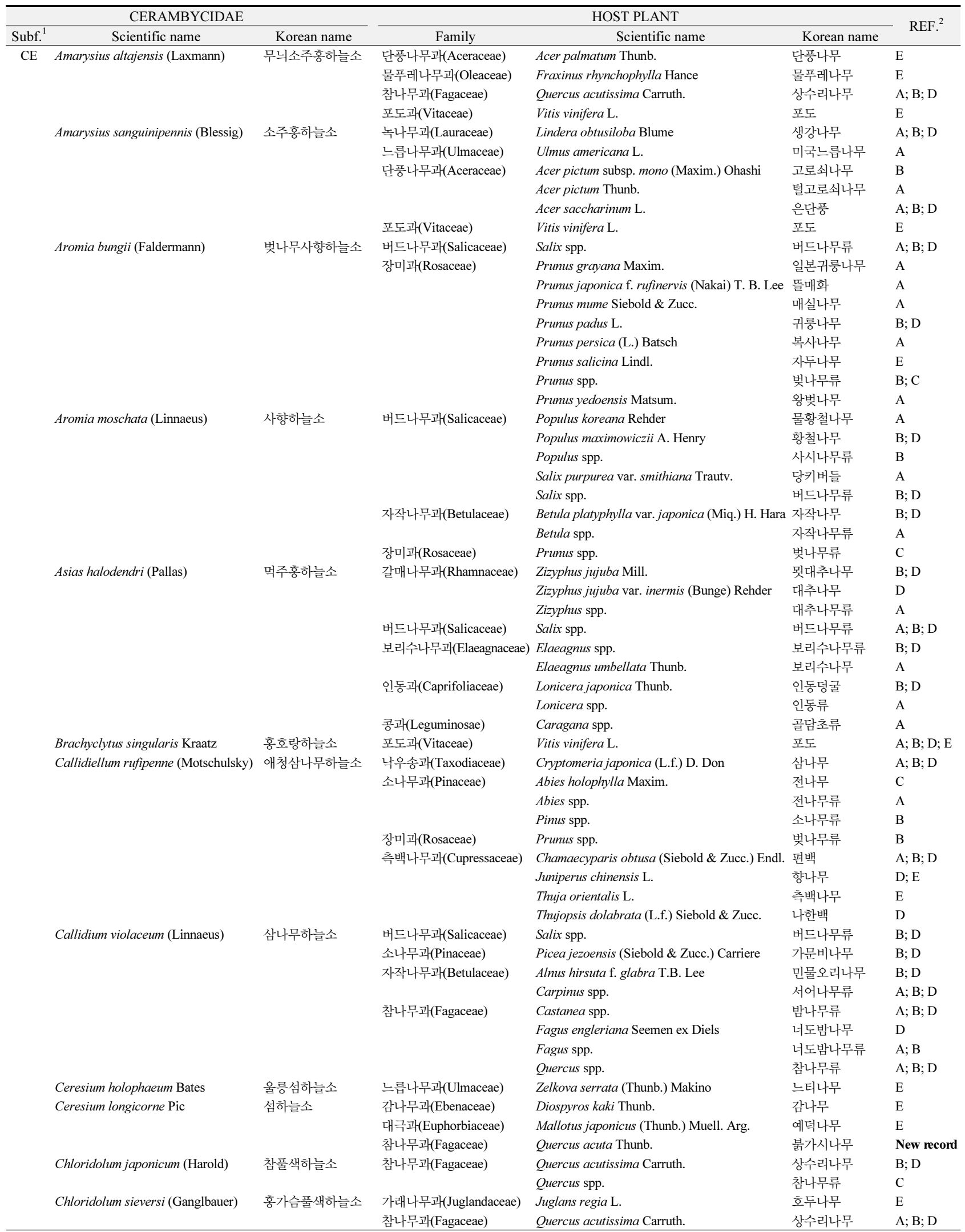




\begin{tabular}{|c|c|c|c|c|c|c|}
\hline \multicolumn{3}{|c|}{ CERAMBYCIDAE } & \multicolumn{3}{|c|}{ HOST PLANT } & \multirow{2}{*}{$\mathrm{REF}^{2}$} \\
\hline Subf. $^{1}$ & Scientific name & Korean name & Family & Scientific name & Korean name & \\
\hline \multirow{3}{*}{\multicolumn{2}{|c|}{ Chloridolum thaliodes Bates }} & \multirow[t]{3}{*}{ 큰풀색하늘소 } & 느릅나무과(Ulmaceae) & Ulmus spp. & 느릅나무류 & $\mathrm{B} ; \mathrm{D}$ \\
\hline & & & \multirow[t]{2}{*}{ 버드나무과(Salicaceae) } & Populus maximowiczii A. Henry & 황철나무 & $\mathrm{B} ; \mathrm{D}$ \\
\hline & & & & Salix spp. & 버드나무류 & A; B; D \\
\hline & Chloridolum viride (Thomson) & \multirow{6}{*}{$\begin{array}{l}\text { 깔따구풀색하늘소 } \\
\text { 대범하늘소 }\end{array}$} & 참나무과(Fagaceae) & Castanea crenata Siebold \& Zucc. & 밤나무 & $\mathrm{E}$ \\
\hline \multirow{5}{*}{\multicolumn{2}{|c|}{ Chlorophorus annularis (Fabricius) }} & & 벼과(Gramineae) & Phyllostachys spp. & 왕대류 & $\mathrm{A} ; \mathrm{B}$ \\
\hline & & & 운향과(Rutaceae) & Citrus spp. & 귤류 & B \\
\hline & & & 자작나무과(Betulaceae) & Betula spp. & 자작나무류 & A \\
\hline & & & 콩과(Leguminosae) & Albizia spp. & 자귀나무류 & $\mathrm{C} ; \mathrm{D}$ \\
\hline & & & 포도과(Vitaceae) & Vitis vinifera $\mathrm{L}$. & 포도 & B \\
\hline \multirow{5}{*}{\multicolumn{2}{|c|}{ Chlorophorus diadema (Motschulsky) }} & \multirow[t]{5}{*}{ 범하늘소 } & 자작나무과(Betulaceae) & Betula spp. & 자작나무류 & B \\
\hline & & & 장미과(Rosaceae) & Malus pumila Mill. & 사과나무 & $\mathrm{B} ; \mathrm{D}$ \\
\hline & & & & Prunus cerasus $\mathrm{L}$. & 구주벚나무 & A \\
\hline & & & & Prunus spp. & 벚나무류 & B \\
\hline & & & 콩과(Leguminosae) & Robinia pseudoacacia $\mathrm{L}$. & 아까시나무 & $\mathrm{B} ; \mathrm{A}$ \\
\hline \multirow{3}{*}{\multicolumn{2}{|c|}{ Chlorophorus japonicus (Chevrolat) }} & \multirow[t]{3}{*}{ 가시범하늘소 } & 감나무과(Ebenaceae) & Diospyros kaki Thunb. & 감나무 & $\mathrm{D}$ \\
\hline & & & 느릅나무과(Ulmaceae) & Zelkova serrata (Thunb.) Makino & 느티나무 & $\mathrm{E}$ \\
\hline & & & 참나무과(Fagaceae) & Quercus acutissima Carruth. & 상수리나무 & $\mathrm{E}$ \\
\hline \multirow{4}{*}{\multicolumn{2}{|c|}{ Chlorophorus motschulskyi (Ganglbauer) }} & 우리범하늘소 & 버드나무과(Salicaceae) & Populus koreana Rehder & 물황철나무 & A \\
\hline & & & & Populus maximowiczii A. Henry & 황철나무 & $\mathrm{B} ; \mathrm{D}$ \\
\hline & & & & Salix spp. & 버드나무류 & $\mathrm{A} ; \mathrm{B} ; \mathrm{D}$ \\
\hline & & & 자작나무과(Betulaceae) & Betula spp. & 자작나무류 & A; B; D \\
\hline & Chlorophorus muscosus (Bates) & 홀쭉범하늘소 & 가래나무과(Juglandaceae) & Platycarya strobilacea Siebold \& Zucc. & 굴피나무 & $\mathrm{E}$ \\
\hline & & & 감나무과(Ebenaceae) & Diospyros kaki Thunb. & 감나무 & $\mathrm{E}$ \\
\hline & & & 느릅나무과(Ulmaceae) & Zelkova serrata (Thunb.) Makino & 느티나무 & $\mathrm{E}$ \\
\hline & Chlorophorus muscosus (Bates) & 홀쭉범하늘소 & 자작나무과(Betulaceae) & Carpinus turczaninowii Hance & 소사나무 & $\mathrm{E}$ \\
\hline & $\begin{array}{l}\text { Chlorophorus quinquefasciatus } \\
\text { (Castelnau et Gory) }\end{array}$ & 네줄범하늘소 & 뽕나무과(Moraceae) & Morus spp. & 뽕나무류 & $\mathrm{B} ; \mathrm{D}$ \\
\hline & & & 장미과(Rosaceae) & Prunus cerasus L. & 구주벚나무 & A \\
\hline & & & & $\begin{array}{l}\text { Prunus serrulata var. spontanea (Maxim.) E. H. } \\
\text { Wilson }\end{array}$ & 벚나무 & B; D \\
\hline & Chlorophorus simillimus (Kraatz) & 육점박이범하늘소 & 가래나무과(Juglandaceae) & Juglans regia $\mathrm{L}$. & 호두나무 & New record \\
\hline & & & 느릅나무과(Ulmaceae) & Zelkova serrata (Thunb.) Makino & 느티나무 & $\mathrm{E}$ \\
\hline & & & 단풍나무과(Aceraceae) & Acer palmatum Thunb. & 단풍나무 & $\mathrm{E}$ \\
\hline & & & 물푸레나무과(Oleaceae) & Fraxinus rhynchophylla Hance & 물푸레나무 & $\mathrm{E}$ \\
\hline & & & 자작나무과(Betulaceae) & Carpinus turczaninowii Hance & 소사나무 & $\mathrm{E}$ \\
\hline & & & 참나무과(Fagaceae) & Quercus acutissima Carruth. & 상수리나무 & $\mathrm{E}$ \\
\hline & & & 층층나무과(Cornaceae) & Cornus controversa Hemsl. & 층층나무 & $\mathrm{E}$ \\
\hline & & & 콩과(Leguminosae) & Albizia julibrissin Durazz. & 자귀나무 & $\mathrm{E}$ \\
\hline & & & & Pueraria lobata (Willd.) Ohwi & 칡 & $\mathrm{E}$ \\
\hline & & & & Robinia pseudoacacia $\mathrm{L}$. & 아까시나무 & $\mathrm{E}$ \\
\hline & Cyrtoclytus capra (Gemar) & 벌호랑하늘소 & 가래나무과(Juglandaceae) & Juglans regia $\mathrm{L}$. & 호두나무 & $\mathrm{E}$ \\
\hline & & & 버드나무과(Salicaceae) & Salix koreensis Andersson & 버드나무 & $\mathrm{E}$ \\
\hline & & & 자작나무과(Betulaceae) & Alnus hirsuta f. glabra T. B. Lee & 민물오리나무 & B \\
\hline & & & & Alnus sibirica Fisch. ex Turcz. & 물오리나무 & $\mathrm{A} ; \mathrm{D}$ \\
\hline & & & & Betula costata Trautv. & 거제수나무 & A; B; D \\
\hline & Cyrtoclytus caproides Bates & - & 감나무과(Ebenaceae) & Diospyros kaki Thunb. & 감나무 & A; B \\
\hline & & & 자작나무과(Betulaceae) & Betula platyphylla var. japonica (Miq.) H. Hara & 자작나무 & $\mathrm{A} ; \mathrm{B}$ \\
\hline & Cyrtoclytus monticallisus Komiya & 넓은홍호랑하늘소 & 느릅나무과(Ulmaceae) & Celtis jessoensis Koidz. & 풍게나무 & E \\
\hline & Demonax transilis Bates & 가시수염범하늘소 & 낙우송과(Taxodiaceae) & Cryptomeria japonica (L.f.) D. Don & 삼나무 & $\mathrm{D}$ \\
\hline & & & 측백나무과(Cupressaceae) & Chamaecyparis obtusa (Siebold \& Zucc.) Endl. & 편백 & $\mathrm{D}$ \\
\hline & Dere thoracica White & 반디하늘소 & 보리수나무과(Elaeagnaceae) & Elaeagnus spp. & 보리수나무류 & $\mathrm{B} ; \mathrm{D}$ \\
\hline & & & & Elaeagnus umbellata Thunb. & 보리수나무 & A \\
\hline & & & 장미과(Rosaceae) & Photinia glabra (Thunb.) Maxim. & 홍가시나무 & A \\
\hline & & & & Prunus japonica f. rufinervis (Nakai) T. B. Lee & 뜰매화 & A \\
\hline & & & & Prunus spp. & 벚나무속 & $\mathrm{B} ; \mathrm{D}$ \\
\hline & & & 참나무과(Fagaceae) & Quercus acuta Thunb. & 붉가시나무 & A; B; D \\
\hline & & & & Quercus aliena Blume & 갈참나무 & $\mathrm{B} ; \mathrm{D}$ \\
\hline & & & 콩과(Leguminosae) & Albizia julibrissin Durazz. & 자귀나무 & $\mathrm{A} ; \mathrm{B} ; \mathrm{D} ; \mathrm{E}$ \\
\hline & Glaphyra kojimai (Matsushita) & 산꼬마벌하늘소 & 층층나무과(Cornaceae) & Cornus controversa Hemsl. & 층층나무 & $\mathrm{E}$ \\
\hline & Glaphyra nitida Obika & 풍게꼬마벌하늘소 & 느릅나무과(Ulmaceae) & Celtis jessoensis Koidz. & 풍게나무 & $\mathrm{E}$ \\
\hline & Leptepania japonica (Hayashi) & 용정하늘소 & 참나무과(Fagaceae) & Castanea spp. & 밤나무속 & $\mathrm{C}$ \\
\hline & Leptoxenus ibidiiformis Bates & 홍줄하늘소 & 녹나무과(Lauraceae) & Lindera obtusiloba Blume & 생강나무 & $\mathrm{E}$ \\
\hline & Margites fulvidus (Pascoe) & 작은하늘소 & 가래나무과(Juglandaceae) & Juglans spp. & 가래나무류 & $\mathrm{D}$ \\
\hline & & & & Platycarya strobilacea Siebold \& Zucc. & 굴피나무 & $\mathrm{E}$ \\
\hline & & & 느릅나무과(Ulmaceae) & Zelkova serrata (Thunb.) Makino & 느티나무 & $\mathrm{E}$ \\
\hline
\end{tabular}




\begin{tabular}{|c|c|c|c|c|c|c|}
\hline \multicolumn{3}{|c|}{ CERAMBYCIDAE } & \multicolumn{3}{|c|}{ HOST PLANT } & \multirow{2}{*}{$\mathrm{REF}^{2}$} \\
\hline Subf. $^{1}$ & Scientific name & Korean name & Family & Scientific name & Korean name & \\
\hline & & & 장미과(Rosaceae) & Prunus salicina Lindl. & 자두나무 & $\mathrm{E}$ \\
\hline & & & 참나무과(Fagaceae) & Castanea crenata Siebold \& Zucc. & 밤나무 & $\mathrm{A} ; \mathrm{D}$ \\
\hline & & & & Quercus acuta Thunb. & 붉가시나무 & New recond \\
\hline & & & 콩과(Leguminosae) & Robinia pseudoacacia $\mathrm{L}$. & 아까시나무 & $\mathrm{A} ; \mathrm{D}$ \\
\hline & & & 현삼과(Scrophulariaceae) & Paulownia tomentosa (Thunb.) Steud. & 참오동나무 & $\mathrm{A} ; \mathrm{D}$ \\
\hline \multirow{11}{*}{\multicolumn{2}{|c|}{ Massicus raddei (Blessig) }} & 하늘소 & 뽕나무과(Moraceae) & Morus spp. & 뽕나무류 & $\mathrm{A} ; \mathrm{B}$ \\
\hline & & & 참나무과(Fagaceae) & Castanea bungeana Blume & 약밤나무 & A \\
\hline & & & & Castanea crenata Siebold \& Zucc. & 밤나무 & $\mathrm{A} ; \mathrm{B} ; \mathrm{D}$ \\
\hline & & & & Castanopsis cuspidata (Thunb.) Schottky & 모밀잣밤나무 & A \\
\hline & & & & Castanopsis sieboldii (Makino) Hatus. & 구실잣밤나무 & $\mathrm{D}$ \\
\hline & & & & Quercus acuta Thunb. & 붉가시나무 & $\mathrm{D}$ \\
\hline & & & & Quercus acutissima Carruth. & 상수리나무 & A; B; D \\
\hline & & & & Quercus dentata Thunb. & 떡갈나무 & $\mathrm{B} ; \mathrm{D}$ \\
\hline & & & & Quercus serrata Thunb. ex Murray & 졸참나무 & A; B; D \\
\hline & & & & Quercus spp. & 참나무류 & $\mathrm{C}$ \\
\hline & & & 현삼과(Scrophulariaceae) & Paulownia spp. & 오동나무류 & $\mathrm{D}$ \\
\hline \multirow{2}{*}{\multicolumn{2}{|c|}{ Molorchus minor (Linnaeus) }} & 꼬마벌하늘소 & 소나무과(Pinaceae) & Abies spp. & 전나무류 & $\mathrm{A} ; \mathrm{D}$ \\
\hline & & & & Picea jezoensis (Siebold \& Zucc.) Carriere & 가문비나무 & $\mathrm{B} ; \mathrm{D}$ \\
\hline \multirow{2}{*}{\multicolumn{2}{|c|}{ Oupyrrhidium cinnabarinum (Blessig) }} & 주홍삼나무하늘소 & 느릅나무과(Ulmaceae) & Ulmus davidiana var. japonica (Rehder) Nakai & 느릅나무 & $\mathrm{E}$ \\
\hline & & & 참나무과(Fagaceae) & Quercus spp. & 참나무류 & $\mathrm{A} ; \mathrm{B} ; \mathrm{D}$ \\
\hline \multirow{3}{*}{\multicolumn{2}{|c|}{ Palaeocallidium chlorizans (Solsky) }} & 청삼나무하늘소 & 느릅나무과(Ulmaceae) & Ulmus spp. & 느릅나무류 & $\mathrm{B} ; \mathrm{D}$ \\
\hline & & & 소나무과(Pinaceae) & Abies spp. & 전나무류 & A; B; D \\
\hline & & & 자작나무과(Betulaceae) & Alnus hirsuta f. glabra T.B. Lee & 민물오리나무 & $\mathrm{B} ; \mathrm{D}$ \\
\hline \multirow{2}{*}{\multicolumn{2}{|c|}{ Perrisus fairmairei Gressitt }} & 작은호랑하늘소 & 가래나무과(Juglandaceae) & Juglans regia $\mathrm{L}$. & 호두나무 & E \\
\hline & & & 느릅나무과(Ulmaceae) & Zelkova serrata (Thunb.) Makino & 느티나무 & $\mathrm{E}$ \\
\hline \multirow{6}{*}{\multicolumn{2}{|c|}{ Phymatodes albicinctus Bates }} & 띠하늘소 & 장미과(Rosaceae) & Malus pumila Mill. & 사과나무 & $\mathrm{B} ; \mathrm{D}$ \\
\hline & & & & Prunus cerasus $\mathrm{L}$. & 구주벚나무 & A \\
\hline & & & & Prunus spp. & 벚나무류 & $\mathrm{B}$ \\
\hline & & & 포도과(Vitaceae) & Vitis coignetiae Pulliat ex Planch. & 머루 & $\mathrm{E}$ \\
\hline & & & & Vitis spp. & 포도류 & $\mathrm{C}$ \\
\hline & & & & Vitis vinifera $\mathrm{L}$. & 포도 & A; B; D \\
\hline & Phymatodes infasciatus (Pic) & 밤띠하늘소 & 포도과(Vitaceae) & Vitis coignetiae Pulliat ex Planch. & 머루 & $\mathrm{E}$ \\
\hline & Phymatodes jiangi Wang et Zheng & 갈색민띠하늘소 & 포도과(Vitaceae) & Vitis vinifera $\mathrm{L}$. & 포도 & $\mathrm{H}$ \\
\hline \multirow{3}{*}{\multicolumn{2}{|c|}{ Phymatodes maaki (Kraatz) }} & 홍띠하늘소 & 다래나무과(Actinidiaceae) & $\begin{array}{l}\text { Actinidia arguta (Siebold \& Zucc.) Planch. ex } \\
\text { Miq. }\end{array}$ & 다래 & $\mathrm{E}$ \\
\hline & & & 포도과(Vitaceae) & Vitis coignetiae Pulliat ex Planch. & 머루 & $\mathrm{E}$ \\
\hline & & & & Vitis vinifera $\mathrm{L}$. & 포도 & $\mathrm{A} ; \mathrm{B} ; \mathrm{D} ; \mathrm{E}$ \\
\hline & Phymatodes murzini Danilevsky & 두줄민띠하늘소 & 포도과(Vitaceae) & Vitis vinifera $\mathrm{L}$. & 포도 & $\mathrm{H}$ \\
\hline & $\begin{array}{l}\text { Phymatodes zemlinae Plavilstshikov et } \\
\text { Anufriev }\end{array}$ & 청날개띠하늘소 & 포도과(Vitaceae) & Vitis vinifera $\mathrm{L}$. & 포도 & $\mathrm{H}$ \\
\hline \multirow{2}{*}{\multicolumn{2}{|c|}{ Plagionotus christophi (Kraatz) }} & 소범하늘소 & 참나무과(Fagaceae) & Quercus acutissima Carruth. & 상수리나무 & $\mathrm{E}$ \\
\hline & & & & Quercus spp. & 참나무류 & A; B; D \\
\hline \multirow{5}{*}{\multicolumn{2}{|c|}{ Plagionotus pulcher (Blessig) }} & 작은소범하늘소 & 느릅나무과(Ulmaceae) & Ulmus davidiana var. japonica (Rehder) Nakai & 느릅나무 & B; D \\
\hline & & & & Ulmus spp. & 느릅나무류 & A \\
\hline & & & 뽕나무과(Moraceae) & Morus spp. & 뽕나무류 & $\mathrm{B} ; \mathrm{D}$ \\
\hline & & & 자작나무과(Betulaceae) & Alnus hirsuta f. glabra T.B. Lee & 민물오리나무 & A; B; D \\
\hline & & & 참나무과(Fagaceae) & Quercus spp. & 참나무류 & A; B; D \\
\hline & Polyzonus fasciatus (Fabricius) & 노랑띠하늘소 & 버드나무과(Salicaceae) & Salix spp. & 버드나무류 & $\mathrm{A} ; \mathrm{B} ; \mathrm{D}$ \\
\hline \multirow{2}{*}{\multicolumn{2}{|c|}{ Pronocera brevicollis (Gebler) }} & 홍가슴삼나무하늘소 & 소나무과(Pinaceae) & Larix olgensis var. amurensis (Kolesn.) Kitag. & 만주잎갈나무 & $\mathrm{D}$ \\
\hline & & & & Larix olgensis var. koreana (Nakai) Nakai & 잎갈나무 & A; B \\
\hline & Pronocera brevicollis (Gebler) & 홍가슴삼나무하늘소 & 소나무과(Pinaceae) & Pinus spp. & 소나무류 & A; B; D \\
\hline \multirow{6}{*}{\multicolumn{2}{|c|}{ Purpuricenus lituratus Ganglbauer }} & 모자주홍하늘소 & 장미과(Rosaceae) & Malus pumila Mill. & 사과나무 & $\mathrm{B} ; \mathrm{D}$ \\
\hline & & & & Malus spp. & 사과나무류 & A \\
\hline & & & & Pyrus pyrifolia var. culta (Makino) Nakai & 배나무 & $\mathrm{B} ; \mathrm{D}$ \\
\hline & & & & Pyrus spp. & 배나무류 & A \\
\hline & & & 참나무과(Fagaceae) & Quercus acutissima Carruth. & 상수리나무 & $\mathrm{E}$ \\
\hline & & & 포도과(Vitaceae) & Vitis vinifera $\mathrm{L}$. & 포도 & $\mathrm{E}$ \\
\hline & $\begin{array}{l}\text { Purpuricenus temminckii } \\
\text { (Guérin-Méneville) }\end{array}$ & 주홍하늘소 & 갈매나무과(Rhamnaceae) & Zizyphus jujuba Mill. & 묏대추나무 & $\mathrm{B} ; \mathrm{D}$ \\
\hline & & & & Zizyphus jujuba var. inermis (Bunge) Rehder & 대추나무 & $\mathrm{A} ; \mathrm{D}$ \\
\hline & & & 벼과(Gramineae) & Phyllostachys bambusoides Sieb. et Zucc. & 왕대 & $\mathrm{E}$ \\
\hline & & & & Phyllostachys spp. & 왕대류 & $\mathrm{A} ; \mathrm{B}$ \\
\hline & & & & Sasa spp. & 조릿대류 & B \\
\hline & & & 장미과(Rosaceae) & Pyrus pyrifolia var. culta (Makino) Nakai & 배나무 & $\mathrm{B} ; \mathrm{D}$ \\
\hline & & & 콩과(Leguminosae) & Albizia spp. & 자귀나무류 & $\mathrm{D}$ \\
\hline
\end{tabular}




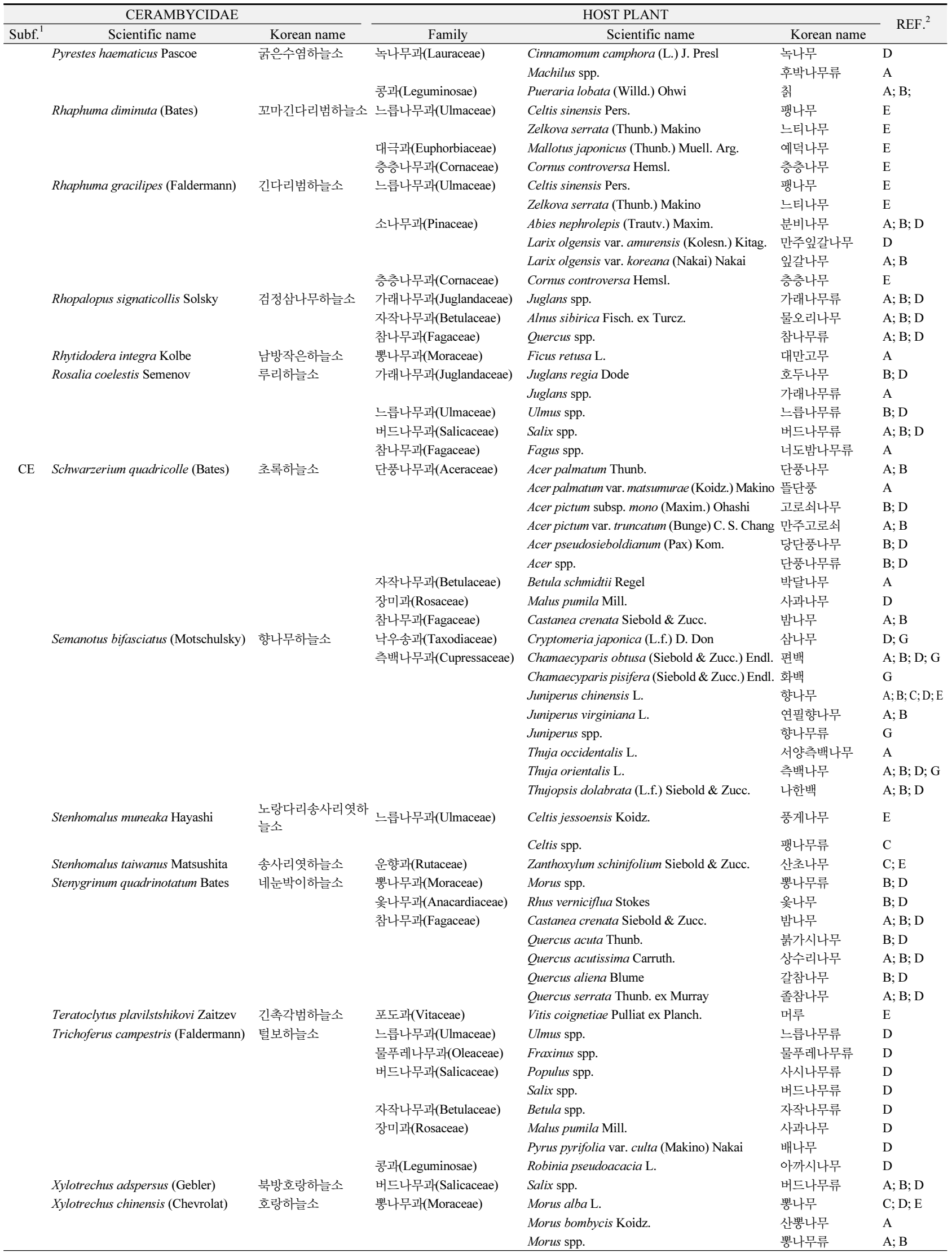




\begin{tabular}{|c|c|c|c|c|c|c|}
\hline \multicolumn{3}{|c|}{ CERAMBYCIDAE } & \multicolumn{3}{|c|}{ HOST PLANT } & \multirow{2}{*}{$\mathrm{REF}^{2}$} \\
\hline Subf. ${ }^{1}$ & Scientific name & Korean name & Family & Scientific name & Korean name & \\
\hline & & & 장미과(Rosaceae) & Malus pumila Mill. & 사과나무 & $\mathrm{B} ; \mathrm{D}$ \\
\hline & & & & Pyrus spp. & 배나무류 & A \\
\hline & Xylotrechus clarinus Bates & 북자호랑하늘소 & 자작나무과(Betulaceae) & Alnus hirsuta f. glabra T.B. Lee & 민물오리나무 & A; B; D \\
\hline & & & & Betula platyphylla var. japonica (Miq.) H. Hara & 자작나무 & A; B; D \\
\hline & Xylotrechus cuneipennis (Kraatz) & 세줄호랑하늘소 & 느릅나무과(Ulmaceae) & Ulmus spp. & 느릅나무류 & $\mathrm{A} ; \mathrm{B} ; \mathrm{D}$ \\
\hline & & & 소나무과(Pinaceae) & Abies spp. & 전나무류 & A; D \\
\hline & & & 참나무과(Fagaceae) & Quercus mongolica Fisch. ex Ledeb. & 신갈나무 & $\mathrm{E}$ \\
\hline & Xylotrechus grayii (White) & 별가슴호랑하늘소 & 느릅나무과(Ulmaceae) & Ulmus davidiana var. japonica (Rehder) Nakai & 느릅나무 & $\mathrm{E}$ \\
\hline & & & 현삼과(Scrophulariaceae) & Paulownia tomentosa (Thunb.) Steud. & 참오동나무 & B \\
\hline & Xylotrechus hircus (Gebler) & 갈색호랑하늘소 & 자작나무과(Betulaceae) & Betula costata Trautv. & 거제수나무 & A; B; D \\
\hline & & & & Betula davurica Pall. & 물박달나무 & A; B; D \\
\hline & Xylotrechus hircus (Gebler) & 갈색호랑하늘소 & 자작나무과(Betulaceae) & Betula platyphylla Sukaczev & 만주자작나무 & $\mathrm{B} ; \mathrm{D}$ \\
\hline & & & & Betula platyphylla var. japonica (Miq.) H. Hara & 자작나무 & A \\
\hline & Xylotrechus pyrrhoderus Bates & 포도호랑하늘소 & 포도과(Vitaceae) & Ampelopsis brevipedunculata (Maxim.) Trautv. & 개머루 & $\mathrm{B} ; \mathrm{D}$ \\
\hline & & & & $\begin{array}{l}\text { Parthenocissus tricuspidata (Siebold \& Zucc.) } \\
\text { Planch. }\end{array}$ & 담쟁이덩굴 & B \\
\hline & & & & Vitis spp. & 포도류 & $\mathrm{C}$ \\
\hline & & & & Vitis vinifera $\mathrm{L}$. & 포도 & $\mathrm{A} ; \mathrm{B} ; \mathrm{D} ; \mathrm{E}$ \\
\hline & Xylotrechus rufilius Bates & 홍가슴호랑하늘소 & 가래나무과(Juglandaceae) & Juglans regia $\mathrm{L}$. & 호두나무 & $\mathrm{E}$ \\
\hline & & & 느릅나무과(Ulmaceae) & Ulmus parvifolia Jacq. & 참느릅나무 & A \\
\hline & & & 단풍나무과(Aceraceae) & Acer pictum subsp. mono (Maxim.) Ohashi & 고로쇠나무 & $\mathrm{B} ; \mathrm{D}$ \\
\hline & & & 물푸레나무과(Oleaceae) & Fraxinus mandshurica Rupr. & 들메나무 & $\mathrm{A} ; \mathrm{B} ; \mathrm{D}$ \\
\hline & Xylotrechus rusticus (Linnaeus) & 줄호랑하늘소 & 느릅나무과(Ulmaceae) & Ulmus spp. & 느릅나무류 & $\mathrm{A} ; \mathrm{D}$ \\
\hline & & & 버드나무과(Salicaceae) & Populus $\mathrm{x}$ canadensis Moench & - & $\mathrm{D}$ \\
\hline & & & & Populus davidiana Dode & 사시나무 & $\mathrm{B} ; \mathrm{D}$ \\
\hline & & & & Populus nigra var. italica Koehne & 양버들 & E \\
\hline & & & & Populus maximowiczii A. Henry & 황철나무 & $\mathrm{B} ; \mathrm{D}$ \\
\hline & & & & Populus sieboldii Miq. & 일본사시나무 & A \\
\hline & & & & Populus spp. & 사시나무류 & A \\
\hline & & & & Salix spp. & 버드나무류 & $\mathrm{A} ; \mathrm{D}$ \\
\hline & & & 자작나무과(Betulaceae) & Alnus hirsuta f. glabra T.B. Lee & 민물오리나무 & $\mathrm{D}$ \\
\hline & & & & Betula platyphylla var. japonica (Miq.) H. Hara & 자작나무 & $\mathrm{B} ; \mathrm{D}$ \\
\hline & & & & Betula spp. & 자작나무류 & A \\
\hline & & & 참나무과(Fagaceae) & Fagus engleriana Seemen ex Diels & 너도밤나무 & $\mathrm{B}$ \\
\hline & & & & Fagus spp. & 너도밤나무류 & A \\
\hline & & & & Quercus acutissima Carruth. & 상수리나무 & A; B; D \\
\hline & & & 느릅나무과(Ulmaceae) & Ulmus spp. & 느릅나무류 & $\mathrm{B} ; \mathrm{G}$ \\
\hline & & & 버드나무과(Salicaceae) & Populus davidiana Dode & 사시나무 & G \\
\hline & & & & Populus maximowiczii A. Henry & 황철나무 & G \\
\hline & & & & Salix spp. & 버드나무류 & B; G \\
\hline & & & 자작나무과(Betulaceae) & Alnus hirsuta f. glabra T.B. Lee & 민물오리나무 & $\mathrm{B} ; \mathrm{G}$ \\
\hline & & & & Betula platyphylla var. japonica (Miq.) H. Hara & 자작나무 & G \\
\hline & & & 피나무과(Tiliaceae) & Tilia spp. & 피나무류 & A; B; D; G \\
\hline & & & 참나무과(Fagaceae) & Quercus acutissima Carruth. & 상수리나무 & G \\
\hline & Xylotrechus salicis Takakuwa et Oda & 닮은줄호랑하늘소 & 버드나무과(Salicaceae) & Populus nigra var. italica Koehne & 양버들 & $\mathrm{E}$ \\
\hline & Xylotrechus yanoi Gressitt & 노랑줄호랑하늘소 & 느릅나무과(Ulmaceae) & Celtis sinensis Pers. & 팽나무 & $\mathrm{C}$ \\
\hline & Xystrocera globosa (Llivier) & 청줄하늘소 & 장미과(Rosaceae) & Prunus persica (L.) Batsch & 복사나무 & A; B; D \\
\hline & & & 콩과(Leguminosae) & Acacia confusa Merr. & 대만아카시아나무 & A \\
\hline & & & & Adenanthera pavonina $\mathrm{L}$. & - & A \\
\hline & & & & Albizia julibrissin Durazz. & 자귀나무 & $\mathrm{E}$ \\
\hline & & & & Albizia lebbeck (L.) Benth. & 비루마작위나무 & A \\
\hline & & & & Albizia spp. & 자귀나무류 & $\mathrm{B} ; \mathrm{D}$ \\
\hline & & & & Chamaecrista spp. & 차풀류 & A \\
\hline & & & 피나무과(Tiliaceae) & Grewia parviflora Bunge & 장구밤나무 & $\mathrm{B} ; \mathrm{D}$ \\
\hline & & & & Grewia spp. & 장구밤나무류 & A \\
\hline DI & Distenia gracilis (Blessig) & 깔따구하늘소 & 뽕나무과(Moraceae) & Ficus carica $\mathrm{L}$. & 무화과나무 & $\mathrm{B}$ \\
\hline & & & & Ficus elastica Roxb. & 인도고무나무 & B \\
\hline & & & 소나무과(Pinaceae) & Abies spp. & 전나무류 & A \\
\hline & & & & Picea jezoensis (Siebold \& Zucc.) Carriere & 가문비나무 & $\mathrm{D}$ \\
\hline & & & & Picea spp. & 가문비나무류 & A \\
\hline & & & & Pinus densiflora Siebold \& Zucc. & 소나무 & $\mathrm{A} ; \mathrm{D}$ \\
\hline & & & 자작나무과(Betulaceae) & Betula davurica Pall. & 물박달나무 & $\mathrm{E}$ \\
\hline LA & Acalolepta degener (Bates) & 애기우단하늘소 & 두릅나무과(Araliaceae) & Aralia elata (Miq.) Seem. & 두릅나무 & $\mathrm{B} ; \mathrm{D}$ \\
\hline & & & & Aralia spp. & 두릅나무류 & A \\
\hline
\end{tabular}




\begin{tabular}{|c|c|c|c|c|c|c|}
\hline \multicolumn{3}{|c|}{ CERAMBYCIDAE } & \multicolumn{3}{|c|}{ HOST PLANT } & \multirow{2}{*}{$\mathrm{REF}^{2}$} \\
\hline Subf. $^{1}$ & Scientific name & Korean name & Family & Scientific name & Korean name & \\
\hline \multirow{5}{*}{\multicolumn{2}{|c|}{ Acalolepta fraudatrix (Bates) }} & 우단하늘소 & 가래나무과(Juglandaceae) & Juglans regia $\mathrm{L}$. & 호두나무 & $\mathrm{E}$ \\
\hline & & & $\begin{array}{l}\text { 굴거리나무과 } \\
\text { (Daphniphyllaceae) }\end{array}$ & Daphniphyllum macropodum Miq. & 굴거리나무 & A; B; D \\
\hline & & & 두릅나무과(Araliaceae) & Fatsia japonica (Thunb.) Decne. \& Planch. & 팔손이 & $\mathrm{D}$ \\
\hline & & & 자작나무과(Betulaceae) & Alnus hirsuta f. glabra T.B. Lee & 민물오리나무 & $\mathrm{B} ; \mathrm{D}$ \\
\hline & & & 콩과(Leguminosae) & Albizia julibrissin Durazz. & 자귀나무 & E \\
\hline \multirow{6}{*}{\multicolumn{2}{|c|}{ Acalolepta luxuriosa (Bates) }} & 큰우단하늘소 & 두릅나무과(Araliaceae) & $\begin{array}{l}\text { Aralia cordata var. continentalis (Kitag.) Y. C. } \\
\text { Chu }\end{array}$ & 독활 & B \\
\hline & & & & Aralia elata (Miq.) Seem. & 두릅나무 & $\mathrm{D} ; \mathrm{E}$ \\
\hline & & & & Fatsia japonica (Thunb.) Decne. \& Planch. & 팔손이 & A; B; D; E \\
\hline & & & & Kalopanax septemlobus (Thunb.) Koidz. & 음나무 & A; B; D \\
\hline & & & 소나무과(Pinaceae) & Abies spp. & 전나무류 & A \\
\hline & & & 피나무과(Tiliaceae) & Tilia amurensis Rupr. & 피나무 & A; B; D \\
\hline \multirow{6}{*}{\multicolumn{2}{|c|}{ Acalolepta sejuncta (Bates) }} & 작은우단하늘소 & 물푸레나무과(Oleaceae) & Fraxinus mandshurica Rupr. & 들메나무 & $\mathrm{A} ; \mathrm{B}$ \\
\hline & & & & Fraxinus rhynchophylla Hance & 물푸레나무 & $\mathrm{D}$ \\
\hline & & & 은행나무과(Ginkgoaceae) & Ginkgo biloba $\mathrm{L}$. & 은행나무 & $\mathrm{D}$ \\
\hline & & & 자작나무과(Betulaceae) & Alnus hirsuta f. glabra T.B. Lee & 민물오리나무 & $\mathrm{B} ; \mathrm{D}$ \\
\hline & & & & Alnus spp. & 오리나무류 & A \\
\hline & & & 층층나무과(Cornaceae) & Cornus controversa Hemsl. & 층층나무 & $\mathrm{E}$ \\
\hline \multirow{5}{*}{\multicolumn{2}{|c|}{ Acanthocinus aedilis (Linnaeus) }} & 솔곤봉수염하늘소 & 소나무과(Pinaceae) & Abies holophylla Maxim. & 전나무 & A; B; D \\
\hline & & & & Picea jezoensis (Siebold \& Zucc.) Carriere & 가문비나무 & A; B; D \\
\hline & & & & Pinus densiflora Siebold \& Zucc. & 소나무 & A; B; D \\
\hline & & & & Pinus koraiensis Siebold \& Zucc. & 잣나무 & A; B; D \\
\hline & & & & Pinus sylvestris $\mathrm{L}$. & 구주소나무 & A \\
\hline \multirow{6}{*}{\multicolumn{2}{|c|}{ Acanthocinus carinulatus Gebler }} & 북방곤봉수염하늘소 & 소나무과(Pinaceae) & Abies spp. & 전나무류 & $\mathrm{D}$ \\
\hline & & & & Larix kaempferi (Lamb.) Carriere & 일본잎갈나무 & A; B; D \\
\hline & & & & Picea jezoensis (Siebold \& Zucc.) Carriere & 가문비나무 & $\mathrm{B} ; \mathrm{D}$ \\
\hline & & & & Pinus koraiensis Siebold \& Zucc. & 잣나무 & A; B; D \\
\hline & & & 자작나무과(Betulaceae) & Alnus hirsuta f. glabra T. B. Lee & 민물오리나무 & B \\
\hline & & & & Alnus sibirica Fisch. ex Turcz. & 물오리나무 & $\mathrm{D}$ \\
\hline \multirow{4}{*}{\multicolumn{2}{|c|}{ Acanthocinus griseus (Fabricus) }} & 곤봉수염하늘소 & 소나무과(Pinaceae) & Picea jezoensis (Siebold \& Zucc.) Carriere & 가문비나무 & B \\
\hline & & & & Pinus spp. & 소나무류 & $\mathrm{A} ; \mathrm{D}$ \\
\hline & & & 자작나무과(Betulaceae) & Alnus hirsuta f. glabra T. B. Lee & 민물오리나무 & B \\
\hline & & & 참나무과(Fagaceae) & Quercus spp. & 참나무류 & A; B \\
\hline \multirow{4}{*}{\multicolumn{2}{|c|}{ Acanthoderes clavipes (Scharank) }} & 큰곤봉수염하늘소 & 버드나무과(Salicaceae) & Populus davidiana Dode & 사시나무 & $\mathrm{B} ; \mathrm{D}$ \\
\hline & & & & Populus sieboldii Miq. & 일본사시나무 & A \\
\hline & & & & Salix spp. & 버드나무류 & B \\
\hline & & & 소나무과(Pinaceae) & Abies spp. & 전나무류 & A \\
\hline \multirow{2}{*}{\multicolumn{2}{|c|}{ Anaerea carcharias (Linnaeus) }} & 백두산긴하늘소 & 버드나무과(Salicaceae) & Populus davidiana Dode & 사시나무 & A; B; D \\
\hline & & & 버드나무과(Salicaceae) & Populus nigra var. italica Koehne & 양버들 & A \\
\hline \multirow{25}{*}{\multicolumn{2}{|c|}{ Anoplophora chinensis (Forster) }} & 알락하늘소 & 가래나무과(Juglandaceae) & Juglans mandshurica Maxim. & 가래나무 & G \\
\hline & & & & Juglans spp. & 가래나무류 & $\mathrm{A} ; \mathrm{D}$ \\
\hline & & & 낙우송과(Taxodiaceae) & Cryptomeria japonica (L.f.) D. Don & 삼나무 & $\mathrm{D} ; \mathrm{G}$ \\
\hline & & & 느릅나무과(Ulmaceae) & Ulmus davidiana var. japonica (Rehder) Nakai & 느릅나무 & B \\
\hline & & & 단풍나무과(Aceraceae) & Acer saccharinum $\mathrm{L}$. & 은단풍 & $\mathrm{D}$ \\
\hline & & & 도금양과(Myrtaceae) & Psidium guajava $\mathrm{L}$. & 반석류 & A \\
\hline & & & 대극과(Euphorbiaceae) & Mallotus japonicus (Thunb.) Muell. Arg. & 예덕나무 & B \\
\hline & & & 때죽나무과(Styracaceae) & Styrax japonicus Siebold \& Zucc. & 때죽나무 & $\mathrm{D} ; \mathrm{G}$ \\
\hline & & & 멀구슬나무과(Meliaceae) & Melia azedarach $\mathrm{L}$ & 멀구슬나무 & B \\
\hline & & & 박과(Cucurbitaceae) & Momordica charantia L. & 여주 & A \\
\hline & & & 버드나무과(Salicaceae) & Populus spp. & 사시나무류 & $\mathrm{B} ; \mathrm{D} ; \mathrm{G}$ \\
\hline & & & & Salix babylonica $\mathrm{L}$. & 수양버들 & A \\
\hline & & & & Salix koreensis Andersson & 버드나무 & $\mathrm{D} ; \mathrm{G}$ \\
\hline & & & & Salix spp. & 버드나무류 & $\mathrm{B} ; \mathrm{C}$ \\
\hline & & & 버즘나무과(Platanaceae) & Platanus occidentalis L. & 양버즘나무 & $\mathrm{B} ; \mathrm{D}$ \\
\hline & & & & Platanus orientalis $\mathrm{L}$. & 버즘나무 & $\mathrm{B} ; \mathrm{G}$ \\
\hline & & & 부처꽃과(Lythraceae) & Lagerstroemia indica $\mathrm{L}$. & 배롱나무 & $\mathrm{D} ; \mathrm{G}$ \\
\hline & & & 뽕나무과(Moraceae) & Broussonetia papyrifera (L.) L'Her. ex Vent. & 꾸지나무 & $\mathrm{A} ; \mathrm{D}$ \\
\hline & & & & Ficus carica $\mathrm{L}$. & 무화과나무 & A; B; D \\
\hline & & & & Morus alba $\mathrm{L}$. & 뽕나무 & $\mathrm{A} ; \mathrm{D} ; \mathrm{G}$ \\
\hline & & & & Morus spp. & 뽕나무류 & B \\
\hline & & & 석류나무과(Punicaceae) & Punica granatum $\mathrm{L}$. & 석류나무 & $\mathrm{D} ; \mathrm{G}$ \\
\hline & & & 아욱과(Malvaceae) & Hibiscus syriacus $\mathrm{L}$. & 무궁화 & G \\
\hline & & & & Hibiscus spp. & 무궁화류 & $\mathrm{D}$ \\
\hline & & & 운향과(Rutaceae) & Atalantia buxifolia (Poir.) Oliv. & 회양밀감ㅇ & A \\
\hline
\end{tabular}




\begin{tabular}{|c|c|c|c|c|c|c|}
\hline \multicolumn{3}{|c|}{ CERAMBYCIDAE } & \multicolumn{3}{|c|}{ HOST PLANT } & \multirow{2}{*}{$\mathrm{REF}^{2}$} \\
\hline Subf. $^{1}$ & Scientific name & Korean name & Family & Scientific name & Korean name & \\
\hline & & & & Citrus junos Siebold ex Tanaka & 유자나무 & $\mathrm{D} ; \mathrm{G}$ \\
\hline & & & & Citrus spp. & 귤류 & $\mathrm{A} ; \mathrm{B}$ \\
\hline & & & & Citrus unshiu S. Marcov. & 귤 & $\mathrm{D} ; \mathrm{G}$ \\
\hline & & & & Poncirus trifoliata Raf. & 탱자나무 & $\mathrm{B} ; \mathrm{D} ; \mathrm{G}$ \\
\hline & & & 자작나무과(Betulaceae) & Alnus firma Siebold \& Zucc. & 사방오리 & $\mathrm{D} ; \mathrm{G}$ \\
\hline & & & & Alnus hirsuta f. glabra T.B. Lee & 민물오리나무 & $\mathrm{B} ; \mathrm{D} ; \mathrm{G}$ \\
\hline & & & 장미과(Rosaceae) & Malus pumila Mill. & 사과나무 & $\mathrm{D} ; \mathrm{B} ; \mathrm{G}$ \\
\hline & & & & Prunus spp. & 벚나무류 & $\mathrm{D}$ \\
\hline & & & & Pyrus pyrifolia var. culta (Makino) Nakai & 배나무 & $\mathrm{B} ; \mathrm{D} ; \mathrm{G}$ \\
\hline & & & & Pyrus ussuriensis Maxim. & 산돌배 & $\mathrm{D}$ \\
\hline & & & & Rosa multiflora Thunb. & 찔레꽃 & $\mathrm{D} ; \mathrm{G}$ \\
\hline & & & & Rosa rugosa Thunb. & 해당화 & $\mathrm{D} ; \mathrm{G}$ \\
\hline & & & & Rosa spp. & 장미류 & B; D \\
\hline & & & & Castanea spp. & 밤나무류 & $\mathrm{D}$ \\
\hline \multirow{16}{*}{\multicolumn{2}{|c|}{ Anoplophora glabripennis (Motschulsky) }} & 유리알락하늘소 & 느릅나무과(Ulmaceae) & Ulmus parvifolia Jacq. & 참느릅나무 & $\mathrm{A} ; \mathrm{B}$ \\
\hline & & & & Ulmus pumila $\mathrm{L}$. & 비술나무 & A; B; D \\
\hline & & & 단풍나무과(Aceraceae) & Acer saccharinum $\mathrm{L}$. & 은단풍 & $\mathrm{F}$ \\
\hline & & & & Acer tegmentosum Maxim. & 산겨릅나무 & New recond \\
\hline & & & & Acer pictum subsp. mono (Maxim.) Ohashi & 고로쇠나무 & $\mathrm{F}$ \\
\hline & & & & Acer pictum var. truncatum (Bunge) C. S. Chang & 만주고로쇠 & $\mathrm{F}$ \\
\hline & & & 대극과(Euphorbiaceae) & Mallotus japonicus (Thunb.) Muell. Arg. & 예덕나무 & A \\
\hline & & & & Vernicia montana Lour. & 일본유동 & B \\
\hline & & & 멀구슬나무과(Meliaceae) & Melia azedarach $\mathrm{L}$. & 멀구슬나무 & A \\
\hline & & & 목마황과(Casuarinaceae) & Casuarina spp. & 목마황류 & A \\
\hline & & & 버드나무과(Salicaceae) & Populus maximowiczii A. Henry & 황철나무 & A; B; D \\
\hline & & & & Salix babylonica $\mathrm{L}$. & 수양버들 & A \\
\hline & & & & Salix spp. & 버드나무류 & A; B; D \\
\hline & & & 버즘나무과(Platanaceae) & Platanus orientalis $\mathrm{L}$. & 버즘나무 & A \\
\hline & & & 장미과(Rosaceae) & Malus spp. & 사과나무류 & A \\
\hline & & & 콩과(Leguminosae) & Cajanus indicus Spreng & 목두 & A \\
\hline \multirow{29}{*}{\multicolumn{2}{|c|}{ Apriona germari (Hope) }} & 뽕나무하늘소 & 가래나무과(Juglandaceae) & Juglans mandshurica Maxim. & 가래나무 & G \\
\hline & & & & Juglans spp. & 가래나무류 & $\mathrm{D}$ \\
\hline & & & & Platycarya strobilacea Siebold \& Zucc. & 굴피나무 & $\mathrm{A} ; \mathrm{B}$ \\
\hline & & & 감나무과(Ebenaceae) & Diospyros kaki Thunb. & 감나무 & $\mathrm{D} ; \mathrm{G}$ \\
\hline & & & 녹나무과(Lauraceae) & Cinnamomum camphora (L.) J. Presl & 녹나무 & $\mathrm{B} ; \mathrm{D} ; \mathrm{G}$ \\
\hline & & & 느릅나무과(Ulmaceae) & Celtis sinensis Pers. & 팽나무 & A; B \\
\hline & & & & Ulmus pumila $\mathrm{L}$. & 비술나무 & A \\
\hline & & & & Ulmus spp. & 느릅나무류 & $\mathrm{B} ; \mathrm{D} ; \mathrm{G}$ \\
\hline & & & 대극과(Euphorbiaceae) & Vernicia fordii (Hemsl.) AiryShaw & 유동 & A \\
\hline & & & 버드나무과(Salicaceae) & Populus alba $\mathrm{L}$. & 은백양 & B \\
\hline & & & & Populus nigra var. italica Koehne & 양버들 & B \\
\hline & & & & Populus maximowiczii A. Henry & 황철나무 & B \\
\hline & & & & Populus spp. & 사시나무류 & $\mathrm{B} ; \mathrm{D} ; \mathrm{G}$ \\
\hline & & & & Salix babylonica $\mathrm{L}$. & 수양버들 & B \\
\hline & & & & Salix gracilistyla Miq. & 갯버들 & A \\
\hline & & & & Salix purpurea var. smithiana Trautv. & 당키버들 & A \\
\hline & & & & Salix spp. & 버드나무류 & B; D; G \\
\hline & & & 벽오동과(Sterculiaceae) & Firmiana simplex (L.) W. F. Wight & 벽오동 & $\mathrm{D} ; \mathrm{G}$ \\
\hline & & & 부처꽃과(Lythraceae) & Lagerstroemia indica $\mathrm{L}$. & 배롱나무 & $\mathrm{A} ; \mathrm{D} ; \mathrm{G}$ \\
\hline & & & 뽕나무과(Moraceae) & Broussonetia kazinoki Siebold & 닥나무 & $\mathrm{D} ; \mathrm{G}$ \\
\hline & & & & Broussonetia papyrifera (L.) L'Her. ex Vent. & 꾸지나무 & $\mathrm{A} ; \mathrm{B} ; \mathrm{D} ; \mathrm{G}$ \\
\hline & & & & Ficus carica $\mathrm{L}$. & 무화과나무 & $\mathrm{A} ; \mathrm{B} ; \mathrm{D} ; \mathrm{E} ; \mathrm{G}$ \\
\hline & & & & Morus alba $\mathrm{L}$. & 뽕나무 & $\mathrm{A} ; \mathrm{D} ; \mathrm{E}$ \\
\hline & & & & Morus spp. & 뽕나무류 & $\mathrm{B} ; \mathrm{G}$ \\
\hline & & & 석류나무과(Punicaceae) & Punica granatum $\mathrm{L}$. & 석류나무 & $\mathrm{D} ; \mathrm{G}$ \\
\hline & & & 장미과(Rosaceae) & Eriobotrya japonica (Thunb.) Lindl. & 비파나무 & $\mathrm{D} ; \mathrm{G}$ \\
\hline & & & & Malus pumila Mill. & 사과나무 & $\mathrm{B} ; \mathrm{D} ; \mathrm{G}$ \\
\hline & & & & Pyrus pyrifolia var. culta (Makino) Nakai & 배나무 & $\mathrm{D} ; \mathrm{G}$ \\
\hline & & & & Pyrus spp. & 배나무류 & $\mathrm{B} ; \mathrm{A}$ \\
\hline
\end{tabular}




\begin{tabular}{|c|c|c|c|c|c|c|}
\hline \multicolumn{3}{|c|}{ CERAMBYCIDAE } & \multicolumn{3}{|c|}{ HOST PLANT } & \multirow{2}{*}{$\mathrm{REF}^{2}$} \\
\hline Subf. $^{1}$ & Scientific name & Korean name & Family & Scientific name & Korean name & \\
\hline & & & 운향과(Rutaceae) & Citrus spp. & 귤속 & $\mathrm{A}$ \\
\hline & & & & Citrus unshiu S. Marcov. & 귤 & $\mathrm{D} ; \mathrm{G}$ \\
\hline & & & 참나무과(Fagaceae) & Quercus acuta Thunb. & 붉가시나무 & $\mathrm{D} ; \mathrm{G}$ \\
\hline & & & 콩과(Leguminosae) & Cajanus spp. & 목두류 & A \\
\hline \multirow{17}{*}{\multicolumn{2}{|c|}{ Bacchisa fortunei (Thomson) }} & 남색하늘소 & 뽕나무과(Moraceae) & Ficus carica $\mathrm{L}$. & 무화과나무 & B \\
\hline & & & 장미과(Rosaceae) & Chaenomeles sinensis (Thouin) Koehne & 모과나무 & $\mathrm{B}$ \\
\hline & & & & Chaenomeles spp. & 명자나무류 & $\mathrm{D}$ \\
\hline & & & & Crataegus cuneata Siebold \& Zucc. & 일본산시나무 & A \\
\hline & & & & Malus micromalus Makino & 개아그배나무 & $\mathrm{B} ; \mathrm{D}$ \\
\hline & & & & Malus pumila Mill. & 사과나무 & $\mathrm{B} ; \mathrm{D}$ \\
\hline & & & & Malus sieboldii (Regel) Rehder & 아그배나무 & B \\
\hline & & & & Photinia glabra (Thunb.) Maxim. & 홍가시나무 & $\mathrm{D}$ \\
\hline & & & & Photinia serratifolia (Desf.) Kalkman & 붉은싹나무 & A \\
\hline & & & & Prunus armeniaca var. ansu Maxim. & 살구나무 & $\mathrm{A} ; \mathrm{B}$ \\
\hline & & & & Prunus domestica $\mathrm{L}$. & 서양자두 & A \\
\hline & & & & Prunus mume Siebold \& Zucc. & 매실나무 & $\mathrm{A} ; \mathrm{B} ; \mathrm{D}$ \\
\hline & & & & Prunus persica (L.) Batsch & 복사나무 & $\mathrm{B}$ \\
\hline & & & & Prunus salicina Lindl. & 자두나무 & B \\
\hline & & & & Prunus spp. & 벚나무류 & $\mathrm{D}$ \\
\hline & & & & Pyrus pyrifolia var. culta (Makino) Nakai & 배나무 & $\mathrm{B} ; \mathrm{D} ; \mathrm{E}$ \\
\hline & & & & Pyrus ussuriensis Maxim. & 산돌배 & $\mathrm{D}$ \\
\hline \multirow{24}{*}{\multicolumn{2}{|c|}{ Batocera lineolata Chevrolat }} & 참나무하늘소 & 느릅나무과(Ulmaceae) & Ulmus davidiana var. japonica (Rehder) Nakai & 느릅나무 & $\mathrm{D}$ \\
\hline & & & & Ulmus spp. & 느릅나무류 & A \\
\hline & & & & Zelkova serrata (Thunb.) Makino & 느티나무 & $\mathrm{D} ; \mathrm{G}$ \\
\hline & & & 버드나무과(Salicaceae) & Populus spp. & 사시나무류 & $\mathrm{B} ; \mathrm{D}$ \\
\hline & & & & Salix spp. & 버드나무류 & $\mathrm{A} ; \mathrm{B} ; \mathrm{D}$ \\
\hline & & & 뽕나무과(Moraceae) & Broussonetia kazinoki Siebold & 닥나무 & G \\
\hline & & & & Ficus carica $\mathrm{L}$. & 무화과나무 & $\mathrm{A} ; \mathrm{B} ; \mathrm{D}$ \\
\hline & & & & Morus spp. & 뽕나무류 & A \\
\hline & & & 자작나무과(Betulaceae) & Alnus hirsuta f. glabra T.B. Lee & 민물오리나무 & $\mathrm{B}$ \\
\hline & & & 장미과(Rosaceae) & Pyrus pyrifolia var. culta (Makino) Nakai & 배나무 & $\mathrm{D}$ \\
\hline & & & & Pyrus ussuriensis Maxim. & 산돌배 & $\mathrm{D}$ \\
\hline & & & 참나무과(Fagaceae) & Castanea crenata Siebold \& Zucc. & 밤나무 & $\mathrm{A} ; \mathrm{B} ; \mathrm{D} ; \mathrm{G}$ \\
\hline & & & & Castanopsis cuspidata (Thunb.) Schottky & 모밀잣밤나무 & A \\
\hline & & & & Castanopsis sieboldii (Makino) Hatus. & 구실잣밤나무 & $\mathrm{A} ; \mathrm{D} ; \mathrm{G}$ \\
\hline & & & & Fagus spp. & 너도밤나무류 & A \\
\hline & & & & Quercus acuta Thunb. & 붉가시나무 & G \\
\hline & & & & Quercus acutissima Carruth. & 상수리나무 & $\mathrm{A} ; \mathrm{B} ; \mathrm{D}$ \\
\hline & & & & Quercus aliena Blume & 갈참나무 & B \\
\hline & & & & Quercus dentata Thunb. & 떡갈나무 & $\mathrm{A} ; \mathrm{B} ; \mathrm{D}$ \\
\hline & & & & Quercus glauca Thunb. & 종가시나무 & $\mathrm{A} ; \mathrm{G}$ \\
\hline & & & & Quercus serrata Thunb. ex Murray & 졸참나무 & $\mathrm{A} ; \mathrm{B} ; \mathrm{D}$ \\
\hline & & & & Quercus spp. & 참나무류 & $\mathrm{C}$ \\
\hline & & & 현삼과(Scrophulariaceae) & Paulownia coreana Uyeki & 오동나무 & G \\
\hline & & & & Paulownia tomentosa (Thunb.) Steud. & 참오동나무 & $\mathrm{B} ; \mathrm{D}$ \\
\hline \multirow{5}{*}{\multicolumn{2}{|c|}{ Compsidia balsamifera Motschulsky }} & 별긴하늘소 & 버드나무과(Salicaceae) & Populus davidiana Dode & 사시나무 & $\mathrm{B} ; \mathrm{D}$ \\
\hline & & & & Populus maximowiczii A. Henry & 황철나무 & $\mathrm{B} ; \mathrm{D}$ \\
\hline & & & & Populus spp. & 사시나무류 & $\mathrm{C}$ \\
\hline & & & & Populus tomentiglandulosa T. B. Lee & 은사시나무 & $\mathrm{E}$ \\
\hline & & & & Salix spp. & 버드나무류 & $\mathrm{B} ; \mathrm{D}$ \\
\hline \multirow{5}{*}{\multicolumn{2}{|c|}{ Compsidia populnea (Linnaeus) }} & 작은별긴하늘소 & 버드나무과(Salicaceae) & Populus alba L. & 은백양 & $\mathrm{D} ; \mathrm{G}$ \\
\hline & & & & Populus davidiana Dode & 사시나무 & $\mathrm{D} ; \mathrm{G}$ \\
\hline & & & & Populus maximowiczii A. Henry & 황철나무 & $\mathrm{A} ; \mathrm{D} ; \mathrm{G}$ \\
\hline & & & & Populus spp. & 사시나무류 & $\mathrm{A} ; \mathrm{G}$ \\
\hline & & & & Salix spp. & 버드나무류 & A \\
\hline & Doius divaricatus (Bates) & 권하늘소 & 소나무과(Pinaceae) & Abies holophylla Maxim. & 전나무 & $\mathrm{E}$ \\
\hline & Egesina bifasciana (Matsushita) & 꼬마하늘소 & 뽕나무과(Moraceae) & Morus alba $\mathrm{L}$. & 뽕나무 & $\mathrm{E}$ \\
\hline & Epiglenea comes Bates & 노랑줄점하늘소 & 가래나무과(Juglandaceae) & Juglans mandshurica Maxim. & 가래나무 & $\mathrm{E}$ \\
\hline \multirow{3}{*}{\multicolumn{2}{|c|}{ Eumecocera impustulata (Motschulsky) }} & 당나귀하늘소 & 느릅나무과(Ulmaceae) & Ulmus davidiana var. japonica (Rehder) Nakai & 느릅나무 & $\mathrm{E}$ \\
\hline & & & 자작나무과(Betulaceae) & Carpinus laxiflora (Siebold \& Zucc.) Blume & 서어나무 & New record \\
\hline & & & 참나무과(Fagaceae) & Castanea crenata Siebold \& Zucc. & 밤나무 & $\mathrm{E}$ \\
\hline & Eupogoniopsis granulatus Lim & 혹민하늘소 & 뽕나무과(Moraceae) & Broussonetia papyrifera (L.) L'Her. ex Vent. & 꾸지나무 & I \\
\hline & $\begin{array}{l}\text { Eutetrapha sedecimpunctata } \\
\text { (Motschulsky) }\end{array}$ & 네모하늘소 & 국화과(Compositae) & Senecio spp. & 금방망이류 & A \\
\hline
\end{tabular}




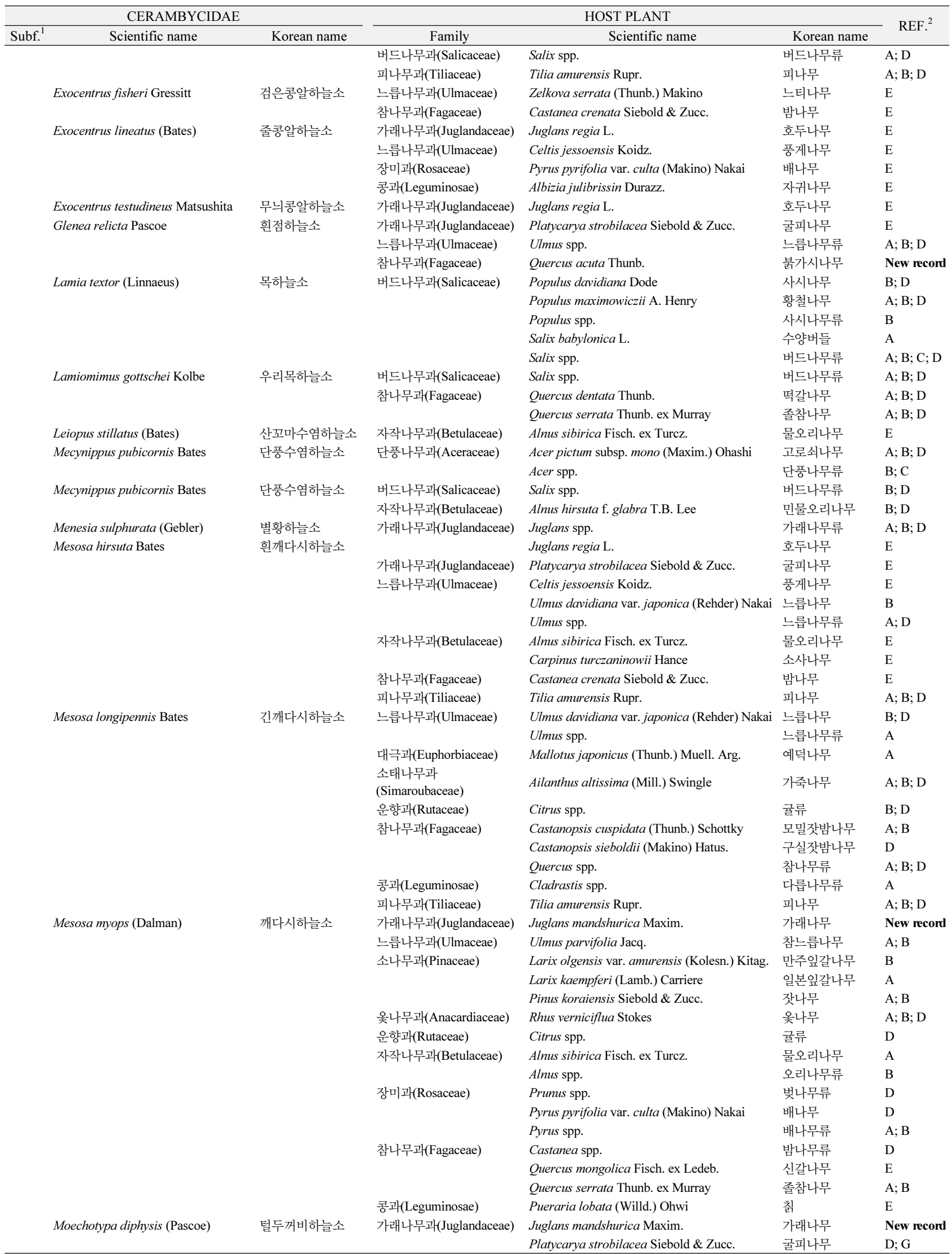




\begin{tabular}{|c|c|c|c|c|c|c|}
\hline \multicolumn{3}{|c|}{ CERAMBYCIDAE } & \multicolumn{3}{|c|}{ HOST PLANT } & \multirow{2}{*}{$\mathrm{REF}^{2}$} \\
\hline Subf. $^{1}$ & Scientific name & Korean name & Family & Scientific name & Korean name & \\
\hline & & & 감나무과(Ebenaceae) & Diospyros kaki Thunb. & 감나무 & $\mathrm{E}$ \\
\hline & & & 자작나무과(Betulaceae) & Carpinus tschonoskii Maxim. & 개서어나무 & $D ; G$ \\
\hline & & & 장미과(Rosaceae) & Pyrus pyrifolia var. culta (Makino) Nakai & 배나무 & E \\
\hline & & & 참나무과(Fagaceae) & Castanea crenata Siebold \& Zucc. & 밤나무 & $\mathrm{D} ; \mathrm{E} ; \mathrm{G}$ \\
\hline & & & & Quercus acuta Thunb. & 붉가시나무 & New record \\
\hline & & & & Quercus acutissima Carruth. & 상수리나무 & $\mathrm{D} ; \mathrm{E} ; \mathrm{G}$ \\
\hline & & & & Quercus myrsinaefolia Blume & 가시나무 & $\mathrm{B} ; \mathrm{D} ; \mathrm{G}$ \\
\hline & & & & Quercus serrata Thunb. ex Murray & 졸참나무 & $\mathrm{D} ; \mathrm{G}$ \\
\hline & & & & Quercus spp. & 참나무류 & $\mathrm{A} ; \mathrm{B}$ \\
\hline \multirow{11}{*}{\multicolumn{2}{|c|}{ Monochamus alternatus Hope }} & 솔수염하늘소 & 낙우송과(Taxodiaceae) & Cryptomeria japonica (L.f.) D. Don & 삼나무 & $\mathrm{A} ; \mathrm{B} ; \mathrm{D} ; \mathrm{G}$ \\
\hline & & & 소나무과(Pinaceae) & Abies firma Sieboid \& Zucc. & 일본전나무 & $\mathrm{A} ; \mathrm{B}$ \\
\hline & & & & Abies holophylla Maxim. & 전나무 & $\mathrm{B} ; \mathrm{D} ; \mathrm{G}$ \\
\hline & & & & Cedrus deodara (Roxb. ex D. Don) G. Don & 개잎갈나무 & $\mathrm{D}$ \\
\hline & & & & Larix spp. & 잎갈나무류 & $\mathrm{D}$ \\
\hline & & & & Picea spp. & 가문비나무류 & $\mathrm{D}$ \\
\hline & & & & Pinus densiflora Siebold \& Zucc. & 소나무 & $\mathrm{A} ; \mathrm{B} ; \mathrm{D} ; \mathrm{G}$ \\
\hline & & & & Pinus koraiensis Siebold \& Zucc. & 잣나무 & $\mathrm{G}$ \\
\hline & & & & Pinus rigida Mill. & 리기다소나무 & G \\
\hline & & & & Pinus strobus L. & 스트로브잣나무 & $\mathrm{D}$ \\
\hline & & & & Pinus thunbergii Parl. & 곰솔 & $\mathrm{A} ; \mathrm{B} ; \mathrm{D} ; \mathrm{G}$ \\
\hline \multirow{11}{*}{\multicolumn{2}{|c|}{ Monochamus saltuarius (Gebler) }} & 북방수염하늘소 & 소나무과(Pinaceae) & Abies spp. & 전나무류 & $\mathrm{G}$ \\
\hline & & & & Picea abies (L.) H. Karst. & 독일가문비 & New record \\
\hline & & & & Picea spp. & 가문비나무류 & $\mathrm{G}$ \\
\hline & & & & Pinus densiflora Siebold \& Zucc. & 소나무 & G \\
\hline & & & & Pinus koraiensis Siebold \& Zucc. & 잣나무 & G \\
\hline & & & & Pinus parviflora Siebold \& Zucc. & 섬잣나무 & G \\
\hline & & & & Pinus strobus L. & 스트로브잣나무 & G \\
\hline & & & & Pinus thunbergii Parl. & 곰솔 & G \\
\hline & & & & Pinus spp. & 소나무류 & $\mathrm{D}$ \\
\hline & & & & Larix kaempferi (Lamb.) Carriere & 일본잎갈나무 & G \\
\hline & & & & Larix spp. & 잎갈나무류 & G \\
\hline \multirow{11}{*}{\multicolumn{2}{|c|}{ Monochamus sutor (Linnaeus) }} & 깨다시수염하늘소 & 소나무과(Pinaceae) & Abies firma Sieboid \& Zucc. & 일본전나무 & $\mathrm{D}$ \\
\hline & & & & Abies koreana Wilson & 구상나무 & A; B; D \\
\hline & & & & Abies nephrolepis (Trautv.) Maxim. & 분비나무 & A \\
\hline & & & & Larix kaempferi (Lamb.) Carriere & 일본잎갈나무 & $\mathrm{B}$ \\
\hline & & & & Larix olgensis var. koreana (Nakai) Nakai & 잎갈나무 & $\mathrm{D}$ \\
\hline & & & & Larix spp. & 잎갈나무류 & A \\
\hline & & & & Picea jezoensis (Siebold \& Zucc.) Carriere & 가문비나무 & $\mathrm{D}$ \\
\hline & & & & Picea spp. & 가문비나무류 & A \\
\hline & & & & Pinus koraiensis Siebold \& Zucc. & 잣나무 & $\mathrm{A} ; \mathrm{B} ; \mathrm{D} ; \mathrm{E}$ \\
\hline & & & & Pinus pumila (Pall.) Regel & 눈잣나무 & $\mathrm{A} ; \mathrm{B} ; \mathrm{D}$ \\
\hline & & & & Pinus sylvestris $\mathrm{L}$. & 구주소나무 & A \\
\hline \multirow{11}{*}{\multicolumn{2}{|c|}{ Monochamus urussovi (Fischer) }} & 수염하늘소 & 소나무과(Pinaceae) & Abies holophylla Maxim. & 전나무 & A \\
\hline & & & & Abies koreana Wilson & 구상나무 & $\mathrm{A} ; \mathrm{D}$ \\
\hline & & & & Abies nephrolepis (Trautv.) Maxim. & 분비나무 & $\mathrm{A} ; \mathrm{E}$ \\
\hline & & & & Abies spp. & 전나무류 & A \\
\hline & & & & Larix kaempferi (Lamb.) Carriere & 일본잎갈나무 & $\mathrm{D}$ \\
\hline & & & & Abies koreana E. H. Wilson & 구상나무 & $\mathrm{B}$ \\
\hline & & & & Abies spp. & 전나무류 & B \\
\hline & & & & Larix olgensis f. viridis (Wilson) Nakai & 좀잎갈나무 & A \\
\hline & & & & Larix spp. & 잎갈나무류 & $\mathrm{B}$ \\
\hline & & & & Picea jezoensis (Siebold \& Zucc.) Carriere & 가문비나무 & A; B; D \\
\hline & & & & Pinus koraiensis Siebold \& Zucc. & 잣나무 & A \\
\hline \multirow{3}{*}{\multicolumn{2}{|c|}{ Niphona furcata (Bates) }} & 짝지하늘소 & 벼과(Gramineae) & $\begin{array}{l}\text { Pseudosasa japonica (Siebold \& Zucc. ex Steud.) } \\
\text { Makino }\end{array}$ & 이대 & $\mathrm{H}$ \\
\hline & & & & Sasa spp. & 조릿대류 & $\mathrm{D}$ \\
\hline & & & 콩과(Leguminosae) & Albizia spp. & 자귀나무류 & $\mathrm{D}$ \\
\hline \multirow{4}{*}{\multicolumn{2}{|c|}{ Nupserha marginella (Bates) }} & 선두리하늘소 & 장미과(Rosaceae) & Malus pumila Mill. & 사과나무 & $\mathrm{B} ; \mathrm{D}$ \\
\hline & & & & Pyrus pyrifolia var. culta (Makino) Nakai & 배나무 & $\mathrm{D}$ \\
\hline & & & & Pyrus pyrifolia (Burm.f.) Nakai & 돌배나무 & B \\
\hline & & & & Pyrus spp. & 배나무류 & A \\
\hline \multirow{3}{*}{\multicolumn{2}{|c|}{ Oberea formosana Pic }} & - & 운향과(Rutaceae) & Euodia daniellii Hemsl. & 쉬나무 & A \\
\hline & & & & Phellodendron amurense Rupr. & 황벽나무 & A \\
\hline & & & 장미과(Rosaceae) & Sorbaria sorbifolia var. stellipila Maxim. & 쉬땅나무 & $\mathrm{B}$ \\
\hline
\end{tabular}




\begin{tabular}{|c|c|c|c|c|c|c|}
\hline \multicolumn{3}{|c|}{ CERAMBYCIDAE } & \multicolumn{3}{|c|}{ HOST PLANT } & \multirow{2}{*}{$\mathrm{REF}^{2}$} \\
\hline Subf. $^{1}$ & Scientific name & Korean name & Family & Scientific name & Korean name & \\
\hline \multirow{2}{*}{\multicolumn{2}{|c|}{ Oberea fuscipennis (Chevrolat) }} & 홀쭉사과하늘소 & 운향과(Rutaceae) & Euodia daniellii Hemsl. & 쉬나무 & $\mathrm{A} ; \mathrm{D}$ \\
\hline & & & & Phellodendron amurense Rupr. & 황벽나무 & $\mathrm{A} ; \mathrm{B} ; \mathrm{D}$ \\
\hline & Oberea herzi Ganglbauer & 우리사과하늘소 & 장미과(Rosaceae) & Malus pumila Mill. & 사과나무 & $\mathrm{B} ; \mathrm{D}$ \\
\hline \multirow{3}{*}{\multicolumn{2}{|c|}{ Oberea inclusa Pascoe }} & 사과하늘소 & 장미과(Rosaceae) & Malus pumila Mill. & 사과나무 & $\mathrm{D}$ \\
\hline & & & & Prunus persica (L.) Batsch & 복사나무 & $\mathrm{D}$ \\
\hline & & & & Pyrus pyrifolia var. culta (Makino) Nakai & 배나무 & $\mathrm{D}$ \\
\hline \multirow{10}{*}{\multicolumn{2}{|c|}{ Oberea japonica Thunberg }} & - & 녹나무과(Lauraceae) & Cinnamomum camphora (L.) J. Presl & 녹나무 & $\mathrm{B}$ \\
\hline & & & 인동과(Caprifoliaceae) & Lonicera japonica Thunb. & 인동덩굴 & A \\
\hline & & & 장미과(Rosaceae) & Cydonia spp. & - & A \\
\hline & & & & Malus pumila Mill. & 사과나무 & $\mathrm{B}$ \\
\hline & & & & Prunus cerasus L. & 구주벚나무 & A \\
\hline & & & & Prunus persica (L.) Batsch & 복사나무 & B \\
\hline & & & & Prunus salicina Lindl. & 자두나무 & $\mathrm{B}$ \\
\hline & & & & Prunus spp. & 벚나무류 & $\mathrm{B}$ \\
\hline & & & & Pyrus pyrifolia (Burm.f.) Nakai & 돌배나무 & B \\
\hline & & & & Pyrus spp. & 배나무류 & A \\
\hline \multirow{7}{*}{\multicolumn{2}{|c|}{ Oberea morio Kraatz }} & 검정사과하늘소 & 자작나무과(Betulaceae) & Alnus spp. & 오리나무류 & $\mathrm{A} ; \mathrm{B} ; \mathrm{D}$ \\
\hline & & & & Carpinus laxiflora (Siebold \& Zucc.) Blume & 서어나무 & $\mathrm{B} ; \mathrm{D}$ \\
\hline & & & & Carpinus spp. & 서어나무류 & A \\
\hline & & & & Corylus heterophylla Fisch. ex Trautv. & 개암나무 & $\mathrm{B} ; \mathrm{D}$ \\
\hline & & & & Corylus spp. & 개암나무류 & A \\
\hline & & & & Ostrya japonica Sarg. & 새우나무 & $\mathrm{B}$ \\
\hline & & & & Ostrya spp. & 새우나무류 & A \\
\hline \multirow{5}{*}{\multicolumn{2}{|c|}{ Oberea oculata (Linnaeus) }} & 두눈사과하늘소 & 버드나무과(Salicaceae) & Salix babylonica $\mathrm{L}$. & 수양버들 & $\mathrm{A} ; \mathrm{B} ; \mathrm{D}$ \\
\hline & & & & Salix caprea $\mathrm{L}$. & 호랑버들 & A \\
\hline & & & & Salix koriyanagi Kimura & 키버들 & $\mathrm{B}$ \\
\hline & & & & Salix purpurea var. smithiana Trautv. & 당키버들 & A \\
\hline & & & & Salix viminalis $\mathrm{L}$ & 육지꽃버들 & $\mathrm{A} ; \mathrm{B}$ \\
\hline \multirow{3}{*}{\multicolumn{2}{|c|}{ Olenecamptus clarus Pascoe }} & 점박이염소하늘소 & 가래나무과(Juglandaceae) & Juglans regia $\mathrm{L}$. & 호두나무 & $\mathrm{E}$ \\
\hline & & & 뽕나무과(Moraceae) & Morus alba $\mathrm{L}$. & 뽕나무 & $\mathrm{A} ; \mathrm{E}$ \\
\hline & & & & Morus spp. & 뽕나무류 & $\mathrm{B} ; \mathrm{D}$ \\
\hline \multirow{3}{*}{\multicolumn{2}{|c|}{ Olenecamptus cretaceus Bates }} & 테두리염소하늘소 & 느릅나무과(Ulmaceae) & Celtis sinensis Pers. & 팽나무 & $\mathrm{E}$ \\
\hline & & & & Zelkova serrata (Thunb.) Makino & 느티나무 & $\mathrm{E}$ \\
\hline & & & 뽕나무과(Moraceae) & Morus spp. & 뽕나무류 & $\mathrm{B} ; \mathrm{D}$ \\
\hline \multirow{2}{*}{\multicolumn{2}{|c|}{ Olenecamptus formosanus Pic }} & 굴피염소하늘소 & 가래나무과(Juglandaceae) & Juglans regia $\mathrm{L}$. & 호두나무 & $\mathrm{E}$ \\
\hline & & & 뽕나무과(Moraceae) & Morus alba $\mathrm{L}$. & 뽕나무 & New record \\
\hline \multirow{2}{*}{\multicolumn{2}{|c|}{$\begin{array}{l}\text { Olenecamptus octopustulatus } \\
\text { (Motschulsky) }\end{array}$}} & 염소하늘소 & 참나무과(Fagaceae) & Quercus spp. & 참나무류 & A; B; D \\
\hline & & & 층층나무과(Cornaceae) & Cornus controversa Hemsl. & 층층나무 & $\mathrm{E}$ \\
\hline & Olenecamptus subobliteratus Pic & 흰염소하늘소 & 가래나무과(Juglandaceae) & Juglans regia $\mathrm{L}$. & 호두나무 & $\mathrm{E}$ \\
\hline \multirow{3}{*}{\multicolumn{2}{|c|}{ Palimna liturata (Bates) }} & 알락수염하늘소 & 단풍나무과(Aceraceae) & Acer pictum subsp. mono (Maxim.) Ohashi & 고로쇠나무 & $\mathrm{A} ; \mathrm{B} ; \mathrm{D}$ \\
\hline & & & & Acer pictum Thunb. & 털고로쇠나무 & A \\
\hline & & & 장미과(Rosaceae) & Malus pumila Mill. & 사과나무 & $\mathrm{B} ; \mathrm{D}$ \\
\hline & Phytoecia rufiventris Gautier & 국화하늘소 & 국화과(Compositae) & Artemisia koidzumii Nakai & 율무쑥 & A \\
\hline & & & & Artemisia princeps Pamp. & 丛 & $\mathrm{E}$ \\
\hline & & & & Aster spp. & 참취류 & A \\
\hline & & & & Chrysanthemum spp. & 쑥갓류 & A \\
\hline & & & 포도과(Vitaceae) & Vitis spp. & 포도류 & $\mathrm{C}$ \\
\hline & Pogonocherus dimidiatus Blessig & 새똥하늘소 & 느릅나무과(Ulmaceae) & Ulmus spp. & 느릅나무류 & $\mathrm{A} ; \mathrm{B} ; \mathrm{D}$ \\
\hline & & & 두릅나무과(Araliaceae) & Aralia elata (Miq.) Seem. & 두릅나무 & $\mathrm{C} ; \mathrm{E}$ \\
\hline & & & & Fatsia japonica (Thunb.) Decne. \& Planch. & 팔손이 & $\mathrm{B} ; \mathrm{D}$ \\
\hline & & & 참나무과(Fagaceae) & Fagus engleriana Seemen ex Diels & 너도밤나무 & $\mathrm{B} ; \mathrm{D}$ \\
\hline & & & & Fagus spp. & 너도밤나무류 & A \\
\hline & & & 피나무과(Tiliaceae) & Tilia amurensis Rupr. & 피나무 & $\mathrm{B} ; \mathrm{D}$ \\
\hline & Psacothea hilaris (Pascoe) & 울도하늘소 & 두릅나무과(Araliaceae) & Dendropanax morbiferus H. Lev. & 황칠나무 & $\mathrm{B}$ \\
\hline & & & & Fatsia japonica (Thunb.) Decne. \& Planch. & 팔손이 & A; B; D \\
\hline & & & 버드나무과(Salicaceae) & Populus maximowiczii A. Henry & 황철나무 & $\mathrm{D}$ \\
\hline & & & 뽕나무과(Moraceae) & Artocarpus altilis (Parkinson) Fosberg & 빵나무 & A \\
\hline & & & & Ficus carica $\mathrm{L}$. & 무화과나무 & $\mathrm{A} ; \mathrm{B} ; \mathrm{D} ; \mathrm{E}$ \\
\hline & & & & Morus alba $\mathrm{L}$. & 뽕나무 & $\mathrm{E}$ \\
\hline & & & & Morus spp. & 뽕나무류 & $\mathrm{A} ; \mathrm{B} ; \mathrm{D}$ \\
\hline & Pterolophia annulata (Chevrolat) & 큰곰보하늘소 & 녹나무과(Lauraceae) & Machilus thunbergii Siebold \& Zucc. & 후박나무 & $\mathrm{E}$ \\
\hline & & & 느릅나무과(Ulmaceae) & Celtis sinensis Pers. & 팽나무 & $\mathrm{E}$ \\
\hline & & & 콩과(Leguminosae) & Albizia julibrissin Durazz. & 자귀나무 & $\mathrm{E}$ \\
\hline
\end{tabular}




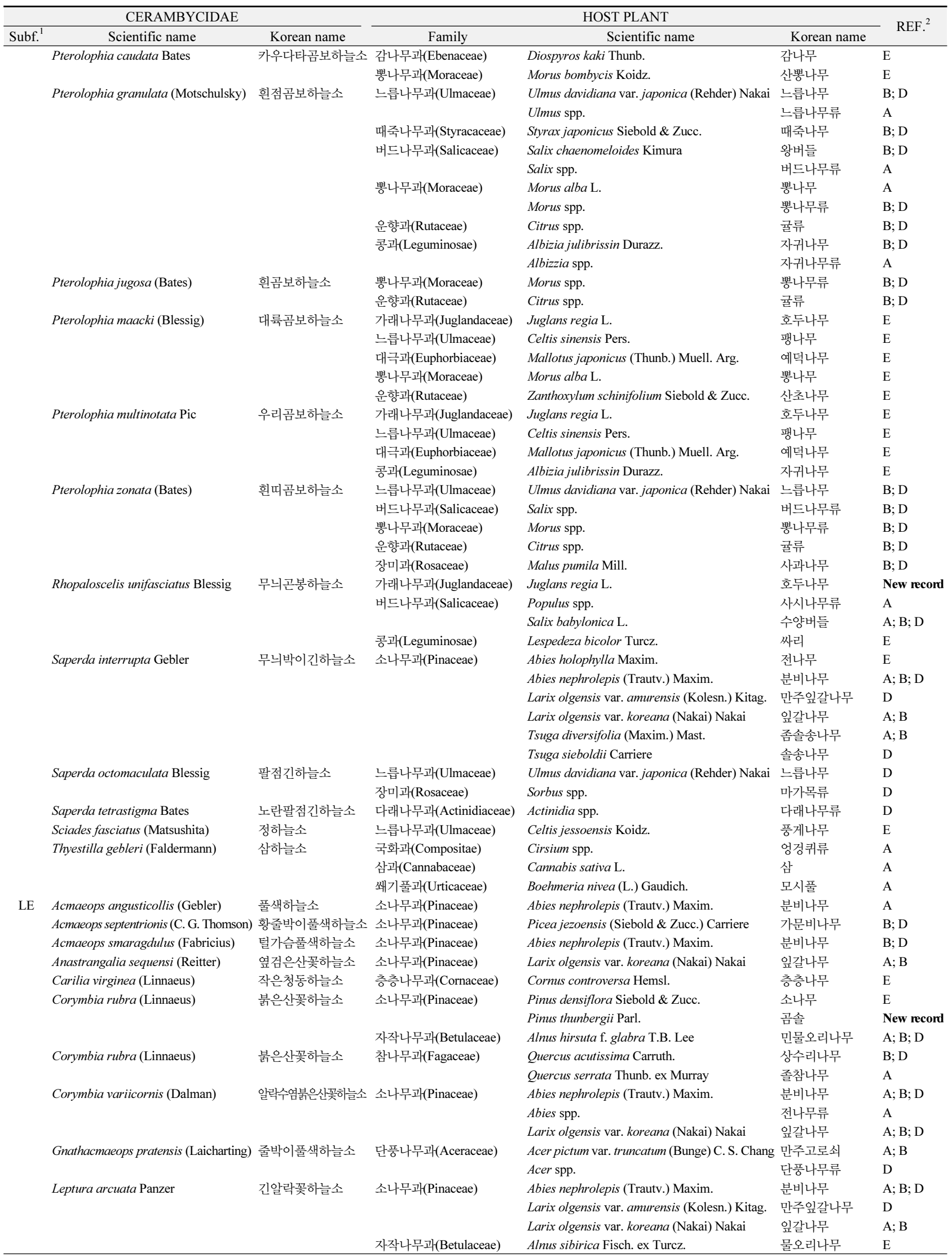




\begin{tabular}{|c|c|c|c|c|c|c|}
\hline \multicolumn{3}{|c|}{ CERAMBYCIDAE } & \multicolumn{3}{|c|}{ HOST PLANT } & \multirow{2}{*}{$\mathrm{REF}^{2}$} \\
\hline Subf. $^{1}$ & Scientific name & Korean name & Family & Scientific name & Korean name & \\
\hline & \multirow[t]{2}{*}{ Leptura duodecimguttata Fabricius } & 열두점박이꽃하늘소 & 자작나무과(Betulaceae) & Betula davurica Pallas & 물박달나무 & $\mathrm{E}$ \\
\hline & & & 장미과(Rosaceae) & Malus pumila Mill. & 사과나무 & New recond \\
\hline & \multirow[t]{4}{*}{ Leptura ochraceofasciata (Motschulsky) } & 넉줄꽃하늘소 & 소나무과(Pinaceae) & Abies spp. & 전나무류 & $\mathrm{A} ; \mathrm{D}$ \\
\hline & & & & Picea jezoensis (Siebold \& Zucc.) Carriere & 가문비나무 & $\mathrm{A} ; \mathrm{B} ; \mathrm{D}$ \\
\hline & & & & Pinus spp. & 소나무류 & $\mathrm{A} ; \mathrm{B} ; \mathrm{D}$ \\
\hline & & & 자작나무과(Betulaceae) & Betula platyphylla var. japonica (Miq.) H. Hara & 자작나무 & $\mathrm{B} ; \mathrm{D}$ \\
\hline & \multirow[t]{3}{*}{ Leptura quadrifasciata Linnaeus } & 북방꽃하늘소 & 버드나무과(Salicaceae) & Salix spp. & 버드나무류 & A; B; D \\
\hline & & & 소나무과(Pinaceae) & Abies spp. & 전나무류 & A \\
\hline & & & 자작나무과(Betulaceae) & Betula platyphylla var. japonica (Miq.) H. Hara & 자작나무 & $\mathrm{A} ; \mathrm{B} ; \mathrm{D}$ \\
\hline & \multirow[t]{3}{*}{ Megaleptura thoracica (Creutzer) } & 홍가슴꽃하늘소 & 소나무과(Pinaceae) & Abies firma Sieboid \& Zucc. & 일본전나무 & $\mathrm{A} ; \mathrm{B} ; \mathrm{D}$ \\
\hline & & & & Larix olgensis var. amurensis (Kolesn.) Kitag. & 만주잎갈나무 & $\mathrm{D}$ \\
\hline & & & & Larix olgensis var. koreana (Nakai) Nakai & 잎갈나무 & $\mathrm{A} ; \mathrm{B}$ \\
\hline & \multirow[t]{7}{*}{ Necydalis major Linnaeus } & 벌하늘소 & 느릅나무과(Ulmaceae) & Ulmus spp. & 느릅나무류 & $\mathrm{B} ; \mathrm{D}$ \\
\hline & & & 버드나무과(Salicaceae) & Populus spp. & 사시나무류 & A \\
\hline & & & & Salix spp. & 버드나무류 & $\mathrm{B} ; \mathrm{D}$ \\
\hline & & & 자작나무과(Betulaceae) & Alnus spp. & 오리나무류 & A \\
\hline & & & 장미과(Rosaceae) & Prunus spp. & 벚나무류 & $\mathrm{A} ; \mathrm{B} ; \mathrm{D}$ \\
\hline & & & 참나무과(Fagaceae) & Fagus engleriana Seemen ex Diels & 너도밤나무 & $\mathrm{D}$ \\
\hline & & & & Fagus spp. & 너도밤나무류 & $\mathrm{A} ; \mathrm{B}$ \\
\hline & \multirow[t]{4}{*}{ Pachyta bicuneata Motschulsky } & 무늬넓은어깨하늘소 & 소나무과(Pinaceae) & Abies nephrolepis (Trautv.) Maxim. & 분비나무 & $\mathrm{A} ; \mathrm{B} ; \mathrm{D}$ \\
\hline & & & & Larix olgensis var. amurensis (Kolesn.) Kitag. & 만주잎갈나무 & $\mathrm{D}$ \\
\hline & & & & Larix olgensis var. koreana (Nakai) Nakai & 잎갈나무 & A; B \\
\hline & & & & Picea spp. & 가문비나무류 & $\mathrm{A} ; \mathrm{B} ; \mathrm{D}$ \\
\hline & \multirow[t]{5}{*}{ Pachyta lamed (Linnaeus) } & 긴무늬넓은어깨하늘소 & 소나무과(Pinaceae) & Abies spp. & 전나무류 & $\mathrm{A} ; \mathrm{B} ; \mathrm{D}$ \\
\hline & & & & Larix olgensis var. amurensis (Kolesn.) Kitag. & 만주잎갈나무 & $\mathrm{D}$ \\
\hline & & & & Larix olgensis var. koreana (Nakai) Nakai & 잎갈나무 & A; B \\
\hline & & & & Picea spp. & 가문비나무류 & $\mathrm{A} ; \mathrm{B} ; \mathrm{D}$ \\
\hline & & & & Pinus spp. & 소나무류 & $\mathrm{A} ; \mathrm{B} ; \mathrm{D}$ \\
\hline & Pedostrangalia femoralis (Motschulsky) & 노랑점꽃하늘소 & 장미과(Rosaceae) & Spiraea spp. & 조팝나무류 & A; B; D \\
\hline & Pidonia similis (Kraatz) & 산줄각시하늘소 & 버드나무과(Salicaceae) & Salix spp. & 버드나무류 & $\mathrm{D}$ \\
\hline & \multirow[t]{2}{*}{ Pidonia suvorovi Baeckmann } & 북방각시하늘소 & 소나무과(Pinaceae) & Larix olgensis var. amurensis (Kolesn.) Kitag. & 만주잎갈나무 & $\mathrm{D}$ \\
\hline & & & & Larix olgensis var. koreana (Nakai) Nakai & 잎갈나무 & $\mathrm{A} ; \mathrm{B}$ \\
\hline & \multirow[t]{10}{*}{ Rhagium inquisitor (Linnaeus) } & 소나무하늘소 & 소나무과(Pinaceae) & Abies holophylla Maxim. & 전나무 & $\mathrm{B} ; \mathrm{D}$ \\
\hline & & & & Abies nephrolepis (Trautv.) Maxim. & 분비나무 & $\mathrm{E}$ \\
\hline & & & & Abies spp. & 전나무류 & A \\
\hline & & & & Larix kaempferi (Lamb.) Carriere & 일본잎갈나무 & A \\
\hline & & & & Picea jezoensis (Siebold \& Zucc.) Carriere & 가문비나무 & A; B; D \\
\hline & & & & Picea koraiensis Nakai & 종비나무 & A \\
\hline & & & & Pinus densiflora Siebold \& Zucc. & 소나무 & A \\
\hline & & & & Pinus spp. & 소나무류 & $\mathrm{B} ; \mathrm{D}$ \\
\hline & & & 자작나무과(Betulaceae) & Betula spp. & 자작나무류 & A \\
\hline & & & 참나무과(Fagaceae) & Fagus spp. & 너도밤나무류 & A \\
\hline & Sachalinobia rugipennis (Newman) & 곰보꽃하늘소 & 소나무과(Pinaceae) & Abies spp. & 전나무류 & $\mathrm{A} ; \mathrm{D}$ \\
\hline & Strangalia attenuata (Linnaeus) & 줄깔따구꽃하늘소 & 참나무과(Fagaceae) & Castanea crenata Siebold \& Zucc. & 밤나무 & $\mathrm{D}$ \\
\hline & & & & Castanea spp. & 밤나무류 & $\mathrm{A} ; \mathrm{B}$ \\
\hline & & & & Quercus spp. & 참나무류 & $\mathrm{A} ; \mathrm{B}$ \\
\hline \multirow[t]{18}{*}{ PR } & Callipogon relictus Semenov & 장수하늘소 & 느릅나무과(Ulmaceae) & Ulmus spp. & 느릅나무류 & $\mathrm{C}$ \\
\hline & & & 물푸레나무과(Oleaceae) & Fraxinus rhynchophylla Hance & 물푸레나무 & $\mathrm{D} ; \mathrm{G}$ \\
\hline & & & & Fraxinus spp. & 물푸레나무류 & $\mathrm{C}$ \\
\hline & & & 자작나무과(Betulaceae) & Carpinus laxiflora (Siebold \& Zucc.) Blume & 서어나무 & $\mathrm{A} ; \mathrm{B} ; \mathrm{D} ; \mathrm{G}$ \\
\hline & & & & Carpinus spp. & 서어나무류 & $\mathrm{C}$ \\
\hline & & & 참나무과(Fagaceae) & Quercus mongolica Fisch. ex Ledeb. & 신갈나무 & $\mathrm{A} ; \mathrm{B} ; \mathrm{D} ; \mathrm{G}$ \\
\hline & & & & Quercus spp. & 참나무류 & $\mathrm{C}$ \\
\hline & Eurypoda batesi Gahan & 사슴하늘소 & 참나무과(Fagaceae) & Castanopsis spp. & 모밀잣밤나무류 & $\mathrm{C}$ \\
\hline & Megopis sinica (White) & 버들하늘소 & 느릅나무과(Ulmaceae) & Ulmus spp. & 느릅나무류 & $\mathrm{A} ; \mathrm{B} ; \mathrm{D} ; \mathrm{G}$ \\
\hline & & & 단풍나무과(Aceraceae) & Acer pictum subsp. mono (Maxim.) Ohashi & 고로쇠나무 & $\mathrm{E}$ \\
\hline & & & 대극과(Euphorbiaceae) & Mallotus japonicus (Thunb.) Muell. Arg. & 예덕나무 & A \\
\hline & & & 물푸레나무과(Oleaceae) & Fraxinus mandshurica Rupr. & 들메나무 & A \\
\hline & & & & Fraxinus spp. & 물푸레나무류 & $\mathrm{A} ; \mathrm{D} ; \mathrm{G}$ \\
\hline & & & 버드나무과(Salicaceae) & Populus alba $\mathrm{L}$. & 은백양 & $\mathrm{B} ; \mathrm{D} ; \mathrm{G}$ \\
\hline & & & & Populus maximowiczii A. Henry & 황철나무 & $\mathrm{A} ; \mathrm{B} ; \mathrm{D} ; \mathrm{G}$ \\
\hline & & & & Populus nigra var. italica Koehne & 양버들 & $\mathrm{B} ; \mathrm{D} ; \mathrm{G}$ \\
\hline & & & & Populus spp. & 사시나무류 & $\mathrm{A} ; \mathrm{B}$ \\
\hline & & & & Populus tomentiglandulosa T. B. Lee & 은사시나무 & $\mathrm{E}$ \\
\hline
\end{tabular}




\begin{tabular}{|c|c|c|c|c|c|c|}
\hline \multicolumn{3}{|c|}{ CERAMBYCIDAE } & \multicolumn{3}{|c|}{ HOST PLANT } & \multirow{2}{*}{$\mathrm{REF}^{2}$} \\
\hline Subf. $^{1}$ & Scientific name & Korean name & Family & Scientific name & Korean name & \\
\hline & & & & Salix babylonica $\mathrm{L}$. & 수양버들 & A \\
\hline & & & & Salix spp. & 버드나무류 & $\mathrm{B} ; \mathrm{D} ; \mathrm{G}$ \\
\hline & & & 뽕나무과(Moraceae) & Morus spp. & 뽕나무류 & A \\
\hline & & & 소나무과(Pinaceae) & Abies firma Sieboid \& Zucc. & 일본전나무 & A; D \\
\hline & & & & Abies holophylla Maxim. & 전나무 & G \\
\hline & & & & Abies spp. & 전나무류 & $\mathrm{A} ; \mathrm{B}$ \\
\hline & & & & Picea jezoensis (Siebold \& Zucc.) Carriere & 가문비나무 & B \\
\hline & & & & Picea spp. & 가문비나무류 & A \\
\hline & & & & Pinus densiflora Siebold \& Zucc. & 소나무 & $\mathrm{A} ; \mathrm{B}$ \\
\hline & & & & Pinus spp. & 소나무류 & A \\
\hline & & & 자작나무과(Betulaceae) & Carpinus laxiflora (Siebold \& Zucc.) Blume & 서어나무 & New record \\
\hline & & & 장미과(Rosaceae) & Malus pumila Mill. & 사과나무 & $\mathrm{B} ; \mathrm{D} ; \mathrm{G}$ \\
\hline & & & & Prunus spp. & 벚나무류 & $\mathrm{D} ; \mathrm{G}$ \\
\hline & & & 참나무과(Fagaceae) & Quercus aliena Blume & 갈참나무 & $\mathrm{B} ; \mathrm{D} ; \mathrm{G}$ \\
\hline & & & & Quercus dentata Thunb. & 떡갈나무 & $\mathrm{A} ; \mathrm{B} ; \mathrm{D} ; \mathrm{G}$ \\
\hline & & & 콩과(Leguminosae) & Robinia pseudoacacia $\mathrm{L}$. & 아까시나무 & $\mathrm{A} ; \mathrm{B} ; \mathrm{D} ; \mathrm{G}$ \\
\hline & & & 현삼과(Scrophulariaceae) & Paulownia tomentosa (Thunb.) Steud. & 참오동나무 & $\mathrm{A} ; \mathrm{B} ; \mathrm{D} ; \mathrm{G}$ \\
\hline & Prionus insularis Motschulsky & 톱하늘소 & 낙우송과(Taxodiaceae) & Cryptomeria japonica (L.f.) D. Don & 삼나무 & $\mathrm{A} ; \mathrm{B}$ \\
\hline & & & 느릅나무과(Ulmaceae) & Ulmus spp. & 느릅나무류 & $\mathrm{A} ; \mathrm{B}$ \\
\hline & & & & Zelkova serrata (Thunb.) Makino & 느티나무 & B \\
\hline & & & 두릅나무과(Araliaceae) & Kalopanax septemlobus (Thunb.) Koidz. & 음나무 & $\mathrm{B}$ \\
\hline & & & 소나무과(Pinaceae) & Abies firma Sieboid \& Zucc. & 일본전나무 & $\mathrm{B} ; \mathrm{D}$ \\
\hline & & & & Abies spp. & 전나무류 & A \\
\hline & & & & Picea jezoensis (Siebold \& Zucc.) Carriere & 가문비나무 & $\mathrm{B} ; \mathrm{D}$ \\
\hline & & & & Picea spp. & 가문비나무류 & A \\
\hline & & & & Pinus densiflora Siebold \& Zucc. & 소나무 & A; B; D \\
\hline & & & 장미과(Rosaceae) & Malus pumila Mill. & 사과나무 & $\mathrm{B} ; \mathrm{D}$ \\
\hline & & & 참나무과(Fagaceae) & Fagus spp. & 너도밤나무류 & A \\
\hline & & & 측백나무과(Cupressaceae) & Chamaecyparis obtusa (Siebold \& Zucc.) Endl. & 편백 & B \\
\hline & & & & Chamaecyparis spp. & 편백류 & A \\
\hline & Psephactus remiger Harold & 반날개하늘소 & 느릅나무과(Ulmaceae) & Celtis sinensis Pers. & 팽나무 & $\mathrm{E}$ \\
\hline & & & 참나무과(Fagaceae) & Fagus japonica Maxim. & 일본너도밤나무 & A \\
\hline & & & & Fagus spp. & 너도밤나무류 & $\mathrm{B} ; \mathrm{D}$ \\
\hline \multirow[t]{31}{*}{ SP } & Arhopalus coreanus (Sharp) & - & 자작나무과(Betulaceae) & Betula spp. & 자작나무류 & $\mathrm{A} ; \mathrm{B}$ \\
\hline & Arhopalus rusticus (Linnaeus) & 큰넓적하늘소 & 낙우송과(Taxodiaceae) & Cryptomeria japonica (L.f.) D. Don & 삼나무 & $\mathrm{A} ; \mathrm{B} ; \mathrm{D}$ \\
\hline & & & 버드나무과(Salicaceae) & Populus maximowiczii A. Henry & 황철나무 & A \\
\hline & & & & Populus nigra var. italica Koehne & 양버들 & A \\
\hline & & & 소나무과(Pinaceae) & Abies spp. & 전나무류 & A \\
\hline & & & & Picea spp. & 가문비나무류 & A \\
\hline & & & & Pinus densiflora Siebold \& Zucc. & 소나무 & $\mathrm{A} ; \mathrm{B} ; \mathrm{D}$ \\
\hline & & & 자작나무과(Betulaceae) & Betula spp. & 자작나무류 & A \\
\hline & & & 측백나무과(Cupressaceae) & Chamaecyparis obtusa (Siebold \& Zucc.) Endl. & 편백 & $\mathrm{A} ; \mathrm{B} ; \mathrm{D}$ \\
\hline & & & & Juniperus chinensis $\mathrm{L}$. & 향나무 & A \\
\hline & Asemum punctulatum Blessig & 꼬마작은넓적하늘소 & 소나무과(Pinaceae) & Abies spp. & 전나무류 & A \\
\hline & & & & Picea jezoensis (Siebold \& Zucc.) Carriere & 가문비나무 & A; B; D \\
\hline & & & & Pinus densiflora Siebold \& Zucc. & 소나무 & $\mathrm{A} ; \mathrm{B} ; \mathrm{D}$ \\
\hline & Asemum striatum (Linnaeus) & 작은넓적하늘소 & 소나무과(Pinaceae) & Abies holophylla Maxim. & 전나무 & $\mathrm{A} ; \mathrm{B} ; \mathrm{D}$ \\
\hline & & & & Abies nephrolepis (Trautv.) Maxim. & 분비나무 & A \\
\hline & & & & Abies spp. & 전나무류 & A \\
\hline & & & & Larix kaempferi (Lamb.) Carriere & 일본잎갈나무 & $\mathrm{A} ; \mathrm{E}$ \\
\hline & & & & Larix olgensis var. koreana (Nakai) Nakai & 잎갈나무 & A \\
\hline & & & & Picea jezoensis (Siebold \& Zucc.) Carriere & 가문비나무 & A; B; D \\
\hline & & & & Picea koraiensis Nakai & 종비나무 & A; B; D \\
\hline & & & & Picea spp. & 가문비나무류 & A \\
\hline & & & & Pinus densiflora Siebold \& Zucc. & 소나무 & $\mathrm{B} ; \mathrm{D}$ \\
\hline & & & & Pinus koraiensis Siebold \& Zucc. & 잣나무 & $\mathrm{A} ; \mathrm{B} ; \mathrm{D}$ \\
\hline & & & & Pinus spp. & 소나무류 & $\mathrm{A} ; \mathrm{B}$ \\
\hline & Cephalallus unicolor (Gahan) & 넓적하늘소 & 소나무과(Pinaceae) & Pinus spp. & 소나무류 & $\mathrm{A} ; \mathrm{B} ; \mathrm{D}$ \\
\hline & Megasemum quadricostulatum Kraatz & 검은넓적하늘소 & 소나무과(Pinaceae) & Abies firma Sieboid \& Zucc. & 일본전나무 & A \\
\hline & & & & Abies spp. & 전나무류 & A; B; D \\
\hline & & & & Picea jezoensis (Siebold \& Zucc.) Carriere & 가문비나무 & $\mathrm{A} ; \mathrm{B} ; \mathrm{D}$ \\
\hline & & & & Pinus spp. & 소나무류 & $\mathrm{A} ; \mathrm{B} ; \mathrm{D}$ \\
\hline & Spondylis buprestoides (Linnaeus) & 검정하늘소 & 낙우송과(Taxodiaceae) & Cryptomeria japonica (L.f.) D. Don & 삼나무 & $\mathrm{A} ; \mathrm{B}$ \\
\hline & & & 소나무과(Pinaceae) & Abies firma Sieboid \& Zucc. & 일본전나무 & $\mathrm{A} ; \mathrm{B}$ \\
\hline
\end{tabular}




\begin{tabular}{|c|c|c|c|c|c|c|}
\hline \multicolumn{3}{|c|}{ CERAMBYCIDAE } & \multicolumn{3}{|c|}{ HOST PLANT } & \multirow{2}{*}{$\mathrm{REF}^{2}{ }^{2}$} \\
\hline Subf. ${ }^{1}$ & Scientific name & Korean name & Family & Scientific name & Korean name & \\
\hline & \multirow{11}{*}{ Tetropium castaneum (Linnaeus) } & \multirow{11}{*}{ 단송넓적하늘소 } & \multirow{11}{*}{$\begin{array}{l}\text { 측백나무과(Cupressaceae) } \\
\text { 소나무과(Pinaceae) }\end{array}$} & Picea spp. & 가문비나무류 & A \\
\hline & & & & Pinus densiflora Siebold \& Zucc. & 소나무 & $\mathrm{A} ; \mathrm{B} ; \mathrm{D}$ \\
\hline & & & & Pinus spp. & 소나무류 & A \\
\hline & & & & Pinus sylvestris $\mathrm{L}$. & 구주소나무 & A \\
\hline & & & & Chamaecyparis obtusa (Siebold \& Zucc.) Endl. & 편백 & $\mathrm{A} ; \mathrm{B}$ \\
\hline & & & & Abies holophylla Maxim. & 전나무 & $\mathrm{B} ; \mathrm{D}$ \\
\hline & & & & Abies nephrolepis (Trautv.) Maxim. & 분비나무 & A \\
\hline & & & & Abies spp. & 전나무류 & A \\
\hline & & & & Larix olgensis var. koreana (Nakai) Nakai & 잎갈나무 & A \\
\hline & & & & Picea abies (L.) H. Karst. & 독일가문비 & A \\
\hline & & & & Picea jezoensis (Siebold \& Zucc.) Carriere & 가문비나무 & $\mathrm{B} ; \mathrm{D}$ \\
\hline & \multirow{5}{*}{ Tetropium gracilicorne Reitter } & \multirow{5}{*}{ 긴단송넓적하늘소 } & \multirow{5}{*}{ 소나무과(Pinaceae) } & Pinus sylvestris L. & 구주소나무 & A \\
\hline & & & & Pinus spp. & 소나무류 & $\mathrm{B} ; \mathrm{D}$ \\
\hline & & & & Abies spp. & 전나무류 & A \\
\hline & & & & Picea jezoensis (Siebold \& Zucc.) Carriere & 가문비나무 & A \\
\hline & & & & Pinus spp. & 소나무류 & A \\
\hline & $\begin{array}{l}\text { Tetropium morishimaorum } \\
\text { Kusama et Takakuwa }\end{array}$ & 애단송넓적하늘소 & 소나무과(Pinaceae) & Larix kaempferi (Lamb.) Carriere & 일본잎갈나무 & $\mathrm{D}$ \\
\hline
\end{tabular}

${ }^{1}$ Subf.: Subfamily (CE, Cerambycinae; DI, Disteniinae; LA, Lamiinae; LE, Lepturinae; PR, Prioninae; SP, Spondylidinae).

${ }^{2}$ REF.: References (A, Cho 1959; B, Ko 1969; C, Lee 1987; D, Chung et al. 1995; E, Kang et al. 2002; F, Williams et al. 2004; G, Shin et al. 2007; H, Lim et al. 2013a; I, Lim et al. 2003b). 